\title{
Genome-wide survey of single-nucleotide polymorphisms reveals fine-scale population structure and signs of selection in the threatened Caribbean elkhorn coral, Acropora palmata
}

\author{
Meghann D Durante ${ }^{1}$ ， Iliana B Baums ${ }^{\text {Corresp. } 1}$ \\ 1 Department of Biology, Pennsylvania State University, University Park, PA, United States \\ Corresponding Author: Iliana B Baums \\ Email address: baums@psu.edu
}

The advent of next-generation sequencing tools has made it possible to conduct fine-scale surveys of population differentiation and genome-wide scans for signatures of selection in non-model organisms. Such surveys are of particular importance in sharply declining coral species, since knowledge of population boundaries and signs of local adaptation can inform restoration and conservation efforts. Here, we use genome-wide surveys of singlenucleotide polymorphisms in the threatened Caribbean elkhorn coral, Acropora palmata, to reveal fine-scale population structure and infer the major barrier to gene flow that separates the eastern and western Caribbean populations between the Bahamas and Puerto Rico. The exact location of this break had been subject to discussion because two previous studies based on microsatellite data had come to differing conclusions. We investigate this contradiction by analyzing an extended set of 11 microsatellite markers including the five previously employed and discovered that one of the original microsatellite loci is apparently under selection. Exclusion of this locus reconciles the results from the SNP and the microsatellite datasets. Scans for outlier loci in the SNP data detected 13 candidate loci under positive selection, however there was no correlation between available environmental parameters and genetic distance. Together, these results suggest that reef restoration efforts should use local sources and utilize existing functional variation among geographic regions in ex situ crossing experiments to improve stress resistance of this species. 
1 Genome-wide survey of single-nucleotide polymorphisms reveals

2 fine-scale population structure and signs of selection in the

3 threatened Caribbean elkhorn coral, Acropora palmata

5 Meghann D Durante ${ }^{1}$, Iliana B Baums ${ }^{1}$

6

$7{ }^{1}$ Department of Biology, Pennsylvania State University, University Park, PA, USA

8

9

10 Corresponding author:

11 Iliana B. Baums

12

13

14

Email address: baums@psu.edu 
15 Abstract

16 The advent of next-generation sequencing tools has made it possible to conduct fine-scale

17 surveys of population differentiation and genome-wide scans for signatures of selection in non-

18 model organisms. Such surveys are of particular importance in sharply declining coral species,

19 since knowledge of population boundaries and signs of local adaptation can inform restoration

20 and conservation efforts. Here, we use genome-wide surveys of single-nucleotide

21 polymorphisms in the threatened Caribbean elkhorn coral, Acropora palmata, to reveal fine-

22 scale population structure and infer the major barrier to gene flow that separates the eastern and

23 western Caribbean populations between the Bahamas and Puerto Rico. The exact location of this

24 break had been subject to discussion because two previous studies based on microsatellite data

25 had come to differing conclusions. We investigate this contradiction by analyzing an extended

26 set of 11 microsatellite markers including the five previously employed and discovered that one

27 of the original microsatellite loci is apparently under selection. Exclusion of this locus reconciles

28 the results from the SNP and the microsatellite datasets. Scans for outlier loci in the SNP data

29 detected 13 candidate loci under positive selection, however there was no correlation between

30 available environmental parameters and genetic distance. Together, these results suggest that reef

31 restoration efforts should use local sources and utilize existing functional variation among

32 geographic regions in ex situ crossing experiments to improve stress resistance of this species. 


\section{Introduction}

There is an ongoing debate about the importance of local recruitment and barriers to gene flow in marine species. Many marine species reproduce via planktonic larvae and strong ocean currents have the potential to carry propagules over long distances. However, a high degree of self-recruitment has been found in a range of species with planktonic larval duration being a poor predictor of genetic structure (Selkoe \& Toonen 2011). The development of cheap genome-scale genotyping is poised to open a new chapter in this discussion (Peterson et al. 2012; Toonen et al. 2013; Wang et al. 2012). American eels for example show panmixia in their central breeding ground in the North Atlantic but single nucleotide polymorphism (SNP) genotyping of adults along the Eastern seaboard revealed local differentiation (Gagnaire et al. 2012). Thus, a wellmixed pool of larvae sorted into environmental niches and so resulted in a structured adult population.

SNPs are ubiquitous throughout the genome, located in coding and non-coding regions, and each locus has a maximum of four alleles (the four bases). This is in contrast to microsatellite loci that consist of tandem repeats, in which allelic variation is determined by the number of tandem repeats and thus can be large. The limited number of alleles at each SNP locus requires a larger number of loci to be assayed to achieve the same power of detecting population genetic structure as a panel of microsatellite loci (Morin et al. 2009; Ryman et al. 2006). The advent of reduced representation sequencing methods have made it possible to develop and assay a large number of SNP loci at a reasonable cost (Altshuler et al. 2000; Hoffberg et al. 2016). Recently, Genotyping by Sequencing (GBS) data including 4,764 SNPs in A cervicornis identified population structure within the Florida Reef tract (Willing et al. 2012) where microsatellite markers did not (Baums et al. 2010). Other flavors of reduced representation sequencing methods (Drury et al. 2016; Toonen et al. 2013; Wang et al. 2012) have yielded information on population structure, and genetic diversity in reef building corals (Drury et al. 2016; Howells et al. 2016a).

Genome-scale genotyping can provide insights into genetic diversity within functional regions of the genome that may be under selection (those genomic regions that code for proteins or regulate transcription of genes). These regions are not commonly surveyed even though they are of interest to conservation managers who want to understand how much capacity there is in a species to adapt to changing conditions (Becks et al. 2010). Statistical methods have been 
66

67

68

developed that allow scanning of SNP loci for signatures of selection. Despite the risk of generating false positive results (Vilas et al. 2012), these methods yield candidate loci that should be substantiated by further testing (Renaut et al. 2011; Sork et al. 2016). The same methods can be used to scan microsatellite loci for signatures of selection (Nielsen et al. 2006; Vasemägi et al. 2005), however, power is often limited by the small number of assayed loci. Acropora palmata is one of a few Caribbean coral species whose population genetic structure has been thoroughly investigated on local and range-wide scales (Baums et al. 2014b; Baums et al. 2005b; Baums et al. 2006a). A range-wide survey of A. palmata population genetic structure using five coral specific polymorphic microsatellite markers showed that $A$. palmata stands are structured into two long-separated populations (Baums et al. 2005a). While most reefs are self-recruiting, A. palmata stands are not inbred and harbor high genetic diversity at these microsatellite loci (Baums et al. 2005b). Bio-physical modeling identified a transient feature in the Mona Passage important in restricting present-day gene flow between the eastern and western population (Baums et al. 2006b). However, it is unclear whether the eastern and western populations differentiated initially due to selection. Subsequent denser sampling of $A$. palmata along the Antilles Island Arc raised the possibility of a hybrid zone across Puerto Rico rather than a clear-cut break between the eastern and western Caribbean at the Mona Passage (Fig 1, Mège et al. 2014).

We sought to refine the location of the east-west population divide and test for the presence of finer scale population differentiation in A. palmata by developing a large number of SNP markers. We assayed genome-wide SNPs in archived samples from two geographic regions in the western A. palmata population (Bahamas and Florida) and two geographic regions in the eastern population [Puerto Rico and the U.S. Virgin Islands (USVI)]. We then compared the results to population structure derived from eleven microsatellite loci. We further aimed to produce a more comprehensive estimate of genetic diversity across the genome using SNPs and screened loci for signatures of selection.

\section{Materials \& Methods}

SAMPLE COLLECTION

Colonies of A. palmata were collected between 2002 and 2010 and previously genotyped (Baums et al. 2014b; Baums et al. 2005b). Unique genets were selected from our database for a 
97 total of 24 samples from each of four geographic regions; the Bahamas, Florida, Puerto Rico and 98 the US Virgin Islands (USVI). The goal was to have eight samples from three different reefs

within each geographic region, however this was not always possible either due to small sample sizes from a particular reef or low clonal diversity of a reef. In those cases, we selected additional unique genets from nearby reefs. See Table 1A for detailed sample information.

We used an extended set of samples to compare the population genetic structure ascertained via microsatellite genotyping to the SNP results. This extended set of samples included 260 samples from six geographic regions; Belize, Florida, Puerto Rico, the USVI, and Curacao (Table 1B). Note that not all SNP-genotyped samples were included in the microsatellite dataset.

\section{LIBRARY PREPARATION}

Coral tissue samples were extracted from ethanol preserved samples using DNeasy Blood \& Tissue Kit (QIAGEN, Hilden, Germany) with the following modifications. Time of incubation in the extraction buffer was increased to 16-20 hours and two $100 \mu$ elutions were performed, the second of which was kept for library production as this fraction contained the high molecular weight DNA. Extracted DNA was then treated with $0.01 \mathrm{mg}$ of RNase A $(10 \mathrm{mg} / \mathrm{ml}$, Amresco Solon, $\mathrm{OH})$. Extraction concentrations ranging from $500 \mathrm{ng}$ to $6 \mu \mathrm{g}$ were double-digested with 10 units of each of the restriction enzymes MluCI (^AATT) and NlaIII (CATG^) (New England Biolabs, Ipswich, MA) following the protocol described by Peterson et al. (2012). Digestions were purified using 1.5X Ampure beads (Beckman Coulter Inc, Brea, CA) and quantified on a Qubit ${ }^{\circledR}$ fluorometer (Life Technologies, Carlsbad, CA). Digested DNA was standardized to 100 ng for each sample before adaptor ligation. Samples were identified with eight 6-bp indices on the NlaIII (rare-cutter) P1 adapter (Supplemental Table 1). Samples were pooled into 12 libraries and then size selected in the range of 200-800 bp on a Pippin-Prep (Sage Science, Beverly, MA). Next, Illumina flow-cell annealing sequences, unique multiplexing indices and sequencing primer annealing regions were added through PCR amplification to the MluCL cut end (See Peterson et al. 2012, Protocol S1, Fig 1). The libraries were enriched with 12 amplification cycles in four separate PCR reactions for each library containing $10 \mu \mathrm{l}$ of Phusion High-Fidelity PCR Master Mix with HF Buffer (New England Biolabs, Ipswich, MA), $2 \mu 1$ of each amplification primer, $1 \mu \mathrm{l}$ of library DNA and $5 \mu \mathrm{l}$ of water (total $20 \mu \mathrm{l}$ ). Samples were 
127 pooled into four libraries each containing 24 samples (Table 2, Supplemental Table 1). Each

128 library was sequenced on one lane of Illumina HiSeq 2000 sequencer (paired-end, 2x150 bp) at

129 the Pennsylvania State Genomics Core Facility. There were two libraries sequenced on each

130 chip. See Peterson et al. (2012) Supplemental File 1 for a detailed protocol. Radseq methods

131 have been used successfully in scleractinian corals (Combosch \& Vollmer 2015; Dimond et al.

132 2017; Forsman et al. 2017) and other marine invertebrates (Lal et al. 2016; Reitzel et al. 2013).

133

134

135

136

137

138

139

140

141

142

143

144

145

146

147

148

149

150

151

152

153

154

155

156

RAW SEQUENCE FILTERING

Raw sequence reads were filtered using the process_radtags in the pipeline STACKS 1.21 (Catchen et al. 2013; Catchen et al. 2011). Barcodes and the RAD-Tag cut sites were identified to de-multiplex the pooled data into individual samples (Suppl Table 2). Reads were discarded that had low quality (with an average raw phred score $<10$ within a 15-base pair slidingwindow), adapter contamination, and uncalled bases. Since all indices differed by at least $2 \mathrm{bp}$, it was possible to correct and retain any index that differed by a single bp from an expected index.

ASSEMBLY

Processed sequences were then aligned to the Acropora digitifera genome (V1.0) (Shinzato et al. 2011) with BowTIE2 (Langmead \& Salzberg 2012) within the GALAXY (BedoyaReina et al. 2013; Blankenberg et al. 2014) framework using end-end read alignment settings in order to remove symbiont and other associated microorganisms. After alignment, paired-end sequencing BAM files were assembled in the ref_map.pl pipeline in STACKS 1.30 with the following parameters. Each paired-end sequencing set was run separately through STACKS to compare results (designated Read1 and Read2) in a one-way ANOVA. The ANOVA used each paired-end read as a technical replicate of the same genomic region. We did this to assess whether we would retrieve similar estimates of $\mathrm{F}_{\text {IS }}$ and heterozygosity from both reads, as expected.

The number of raw reads required to report a stack was $m=5$. The number of mismatches allowed between loci when building the catalog was $n=4$. SNPs with a log-likelihood of less than -10 were removed as reads with poor log-likelihoods tend to have sequencing error and/or low coverage. Two of the barcodes (TCGAT and CGATC) had few sequence reads across all four geographic regions with all Illumina lanes being affected, and samples with these barcodes were removed before assembly in STACKS. 
158

159

160

161

162

163

164

165

166

167

168

169

170

171

172

173

174

175

176

177

178

179

\section{GENOME COVERAGE}

BEDTOOLS (Quinlan \& Hall 2010) was used to create a histogram of genome coverage for each sample from the BowTIE2 BAM format alignment files. All positions with a depth of coverage greater to or equal to 20 were combined into a single bin in the histogram. Data from all geographic regions were averaged (excluding samples with barcodes TCGAT and CGATC) and a cumulative distribution of sequencing coverage was then plotted in SiGMAPLOT v12.

\section{POPULATION GENETIC STATISTICS}

We explored values for several parameters relevant to population genetic analyses. In the Populations module in STACKS 1.30 we required a locus to be present in all regions for all analyses (option $-\mathrm{p}=4$ ). For each locus, we then set the minimum percentage of individuals in a region required to have data for that locus to $40 \%$ or $60 \%$ (option $-r$ ). Further, we set the minimum minor allele frequency (MAF) required to process a nucleotide site at a locus (option min_maf) to $0.025,0.05$ and 0.075 . A $p$-value correction was applied to $\mathrm{F}_{\mathrm{ST}}$ scores, so that if a $\mathrm{F}_{\mathrm{ST}}$ score was not significantly different from 0 (according to Fisher's Exact Test) the value was set to 0. Additionally, only one random SNP from any RAD locus was written to the STRUCTURE export file in order to prevent linked loci from being processed. Read 1 and Read 2 STRUCTURE export files were combined and duplicate loci removed randomly between reads. $\mathrm{F}_{\mathrm{ST}}(p$ value $<0.05$ ) was calculated in STACKS. $\mathrm{F}_{\mathrm{IS}}$ and $\mathrm{F}_{\mathrm{ST}}$ distributions are included in the supplement (Supplemental Figure 1, 2).

\section{CLUSTERING ANALYSES}

Clustering analyses for the SNP and microsatellite analysis were performed in the program STRUCTURE 2.3.4 (Falush et al. 2003; Hubisz et al. 2009) using the admixture model with correlated allele frequencies. The analysis included the following parameters: 100,000 burnin iterations and 1,000,000 Markov chain Monte Carlo repetitions, with and without a population prior, for a total of three replicates for each value of $\mathrm{K}$. K values ranged from 2 to 5 . The most likely value for K was determined by CLUMPAK (Kopelman et al. 2015) BEST K which uses either the Evanno method (Evanno et al. 2005) or $\mathrm{LN}(\mathrm{PR}(\mathrm{X} \mid \mathrm{K})$ values to identify the $\mathrm{K}$ for which $\operatorname{PR}(K=K)$ is the highest as described in STRUCTURE's manual section 5.1. Results of the three structure runs were merged with CLUMPAK (Kopelman et al. 2015). Based on our exploration of 
187 minor allele frequency (MAF) cut off values and the percent of individuals per geographic region 188 allowed to miss a locus $(\% \mathrm{M})$, we report results for $\mathrm{MAF}=0.05$ and for a $\% \mathrm{ML}=60 \%$ in the

189

190

191

192

193

194

195

196

197

198

199

200

201

202

203

204

205

206

207

208

209

210

211

212

213

214

215

216

main text (Fig 2). STRUCTURE clustering analyses for minor allele frequencies cutoffs of 0.025 and 0.075 are included in the supplement (Supplemental Figure 3 ). STRUCTURE clustering analysis when the minor allele frequency cutoff was 0.05 and when outlier loci were removed, is also included in the supplement (Supplemental Figure 4). STRUCTURE clustering analysis when the minor allele frequency cutoff was 0.05 and when a locus must be present in at least $40 \%$ of individuals in a geographic region, is included in the supplement (Supplemental Figure 5). PCA clustering analysis, for SNPs and microsatellites, using adegenet (Jombart 2008) is included in the supplement (Supplemental Figure 6).

Previously genotyped samples $(\mathrm{n}=260)$ at 10 and 11 microsatellite markers $(181,182$, 192, 207, 0585, 0513, 2637, 007, 9253, 5047, with and without locus 166) (Baums et al. 2009; Baums et al. 2005a) were also analyzed with STRUCTURE 2.3.4 (Falush et al. 2003; Hubisz et al. 2009) using the admixture model with correlated allele frequencies (See Table 1 for sample information). The analysis included the following parameters; 100,000 burn-in iterations and 1,000,000 MCMC repetitions, with and without a population prior, for a total of 3 replicates for each value of $K$. K values tested ranged from 2 to 7.

\section{MANTEL TESTS}

Data on temperature, salinity, dissolved oxygen $(\mathrm{ml} / \mathrm{l})$, and phosphates was downloaded from the World Ocean Atlas 2013 (WOA13 V2, Suppl Table 3). Silicates and nitrates were not used as there was not sufficient data for all locations. For the Bahamas, Puerto Rico, and the USVI the geographic center point among several sampling sites was used because reefs were further apart than in Florida. For all data, the statistical mean of the annual average of years 1955-2012 and depths of 0-10 $\mathrm{m}$ was used. Grid sizes were $1 / 4^{\circ}$ for temperature and salinity, and $1^{\circ}$ for dissolved oxygen $(\mathrm{ml} / 1)$, and phosphates ( $\left.\mu \mathrm{mol} / \mathrm{l}\right)$ (Supplemental Table 2). SPSS V22 was used to calculate a dissimilarity matrix expressed as the Euclidean distances between geographic regions based on the above environmental data. To obtain a single GPS location for each geographic region we had to average the latitude and longitude coordinates for all samples in each region. Then GenAlEx v6.501 (Peakall \& Smouse 2006) was used to calculate a pairwise geographic distance matrix between the four geographic regions. GenAlEx v6.501 (Peakall \& 
217 Smouse 2006) was used to calculate Mantel multi-comparison tests between the geographic

218 distance matrix, $\mathrm{F}_{\mathrm{ST}}$ pairwise matrix between geographic regions from STACKS, and the

219 environmental dissimilarity matrix.

220 OUTLIER ANALYSIS

221 Two independent methods were applied to identify putative loci under selection. The first 222 program used was LositAN (Antao et al. 2008) which utilizes the method of Beaumont and 223 Nichols (1996a) to identify loci under selection based on the joint distributions of expected 224 heterozygosity and $\mathrm{F}_{\mathrm{ST}}$ under an island model of migration. The following settings were used for 225 the SNP and the microsatellite datasets. The neutral mean setting was selected in which during 226 an initial run (100,000 simulations), a candidate subset of selected loci (outside the $95 \%$ 227 confidence interval) were identified and removed. Then the distribution of neutral $\mathrm{F}_{\mathrm{ST}}$ was 228 computed using 100,000 simulations and a bisection approximation algorithm (Antao et al. 229 2008), with the following options, force mean $\mathrm{F}_{\mathrm{ST}}$, infinite alleles mutation model, and a 230 confidence interval 0.99 . A FDR $<0.1$ correction for multiple testing was applied. Loci outside 231 the upper and lower confidence areas were identified as candidates affected by positive and 232 balancing selection, respectively (Supplemental Table 4). All geographic regions were analyzed 233 together. Outliers identified as being under balancing selection were not considered as these are 234 more likely to be false positives (Lotterhos \& Whitlock 2014). The positive outlier loci $(\mathrm{p}<0.01)$ were blasted against the NCBI nr, UniProt, and Trembl databases with parameters of expected value $=0.00001$, gap opening penalty $=11$, gap extension penalty $=1$, length of initial exact match $($ word size $)=6$ and scoring matrix $=$ BLOSUM62 using BLASTX 2.2.32+ (Altschul et al. 1997).

The STACKS exported GENEPOP dataset was also reformatted with PGDSPIDER version 2.0.5.2 (Lischer \& Excoffier 2012) to a GESTE file. The method of Foll and Gaggiotti (2008) was performed using BAYESCAN 2.0 (http://www-leca.ujf-grenoble.fr/logiciels.html). For each locus, the probability of it being under selection was inferred using the Bayes factor (BF). Based on Jeffreys' (1961) scale of evidence, a $\log 10$ BF of 1.5-2.0 is interpreted as "strong evidence"

244 for departure from neutrality at that locus and corresponds to a posterior probability between

245 0.97-0.99. For our analysis, the estimation of model parameters was set as 20 pilot runs of 5,000 246 iterations each, followed by 50,000 iterations. 


\section{Results}

Summary statistics

Illumina sequencing of the RAD libraries generated 49.3 million reads per pool of eight

251

252

253

254

255

256

257

258

259

260

261

262

263

264

265

266

267

268

269

270

271

272

273

274

275

276

277

samples, averaging 6.2 million $150 \mathrm{bp}$ reads per sample prior to quality filtering. After quality filtering, 4.99 million reads per sample (81\%) were retained on average (Table 2). Pools had similar numbers of reads after processing (mean $=39.9$ million per pool, $\mathrm{SD}=4.95$ million, oneway ANOVA, $\mathrm{F}=2.638, \mathrm{p}>0.1$ ). The average $\% \mathrm{GC}$ content for Read 1 and 2 was 41.7 and 39.6, respectively. The percentage of polymorphic sites per genomic region varied little among geographic regions, from 0.150 to $0.173 \%$ (Table 3 ). The average observed heterozygosity in variant sites was $22 \%$. Overall $F_{\text {IS }}$ values, when considering all sites with a minor allele frequency cutoff $\mathrm{a} \geq 0.05$, were close to 0 and hence provided no evidence of inbreeding (Table 3). However, when only considering variant positions within the region of Florida, $F_{\text {IS }}$ values were negative $\left(\mathrm{F}_{\text {is }}=-0.0086\right)$, indicating an excess of heterozygosity. Using the two paired-end read sets as replicates, a one-way ANOVA was performed for each variable (Table 4). Summary statistics for all geographic regions were found to be similar. Alignment of A. palmata SNPs to the published $A$. digitifera genome indicated that on average, $2.5 \%$ percent of the $A$. digitifera genome had sequence coverage at a stack depth of 5 (Supplemental Figure 7). All four geographic regions produced similar sequence coverage.

Population genetics

A total of 390 SNPS were identified after filtering and including a minor allele frequency cutoff $\mathrm{a} \geq 0.05$ (Table 3 ). This included 219 for Read 1 and 176 for Read 2 from the paired-end sequencing (5 SNPs were identical between reads and only considered once). Analysis of Molecular Variance (AMOVA) revealed patterns of genetic differentiation among geographic regions (Table 4). This was also evident when the 307 SNPs (analysis included only one SNP per $150 \mathrm{bp}$ locus) were subjected to a multi-locus clustering analysis in STRUCTURE. Samples from Florida clustered first, followed by the Bahamas at $K=3$. Puerto Rico and the USVI were not distinguishable until $\mathrm{K}=4$, (Fig 2). CLUMPAK BEST K (Kopelman et al. 2015) indicated that $\mathrm{K}=3$ was the most likely K-value, after both the Evanno method and $\operatorname{LN}(\operatorname{PR}(\mathrm{X} \mid \mathrm{K})$ values, regardless of whether the geographic region was used as a prior. 
To compare to the SNP analysis, microsatellite data from samples collected in six regions

279

280

281

282

283

284

285

286

287

288

289

290

291

292

293

294

295

296

297

298

299

300

301

302

303

304

305

306

307

308 were analyzed in STRUCTURE using the geographic region as a prior (Supplemental Table 5). At $\mathrm{K}=2$, a western (including Belize, Florida, Bahamas and Puerto Rico) and an eastern cluster (including the USVI and Curacao) was evident (Fig 3A). At $\mathrm{K}=3$, an isolation-by-distance like pattern was apparent in the western cluster (Fig 3B). K=4 was the most likely K-value, after both the Evanno method and LN(PR $(X \mid K)$ values, based on 11 microsatellite markers (Kopelman et al. 2015). Florida and Belize grouped as one cluster, and Puerto Rico and the Bahamas as the second, with the USVI as the third and Curacao as an admixed fourth cluster (Fig 3C).

According to the outlier analysis in LOSITAN, microsatellite locus 166 was identified as a potential outlier and thus possibly under selection. It was therefore excluded from the analysis in STRUCTURE. This resulted in more comparable results to the SNP analysis with the most likely K-value being 3, after both the Evanno method and LN(PR(X|K) values (Kopelman et al. 2015). Again, the first separation was between a western and an eastern cluster, however this time Puerto Rico assigned to the eastern cluster with an isolation-by-distance like pattern appearing between the west and east (Fig 3D). At the most likely K of 3, Curacao now formed a separate cluster. At $\mathrm{K}=4$, the Bahamas started to separate from the remainder of the western region similar to what was observed in the SNP clustering analysis (Fig 3E).

Environmental drivers of population structure

A Mantel test showed a significant positive relationship in the SNP dataset between pairwise $\mathrm{F}_{\mathrm{ST}}$ values and geographic distance $\left(\mathrm{R}^{2}=0.65, p=0.05\right)$ consistent with the microsatellite results (10 loci) from the Florida, Bahamas, Puerto Rico, and Curacao samples only (Fig4C, Fig4D). Correlations between environmental factors including average temperature, salinity, dissolved oxygen, and pairwise $\mathrm{F}_{\mathrm{ST}}$ values or geographic distance were not significant (Fig4A, Fig4B).

Loci under selection

BAYESCAN and LOSITAN identified 2 and 12 SNPs (Supplemental Table 4) that showed signs of positive selection when including all four geographic regions, one of which was identified by both programs (a total of 13 unique loci identified between both programs).

Outliers accounted for $3.3 \%$ of the total SNPs, consistent with other studies in which $\mathrm{F}_{\mathrm{ST}}$ outlier loci have represented a substantial fraction of the total loci investigated (2-10\%) (Nosil et al. 
309

310

311

312

313

314

315

316

317

318

319

320

321

322

323

324

325

326

327

328

329

330

331

332

333

334

335

336

337

2009). Annotation of the candidate loci proved difficult as only $23 \%$ produced significant hits when queried against the NCBI NR database, Uniprot, and Trembl; with two of the hits being annotated as unconventional myosin-IXb isoform X7 and tyrosine-protein kinase transmembrane receptor ROR1-like. Screening of the microsatellite loci identified locus 166 as an outlier under positive selection, yet no annotation information of this locus is currently available.

\section{Discussion}

\section{Comparison with previous Acropora gene flow studies}

The previous range-wide survey of $A$. palmata population genetic structure using five, presumed neutrally evolving microsatellite markers showed that while most reefs are selfrecruiting, A. palmata stands are not inbred and harbor high microsatellite genetic diversity (Baums et al. 2005b). Furthermore, A. palmata stands were structured into two long-separated populations, one in the eastern and one in the western Caribbean (Baums et al. 2005b). Here, we report that genome-wide SNPs (MAF $\geq 0.05$ ) resolved further population structure in the endangered reef-building coral, A. palmata from Florida to the USVI compared to previous microsatellite-based analyses.

It was recently suggested that the East-West divide of $A$. palmata lies not in the Mona Passage (Baums et al. 2005b; Baums et al. 2006b) but rather to the east of Puerto Rico (Fig 1, Mège et al. 2014). The 307 SNPs analyzed here confirm earlier findings that Puerto Rico and the USVI regions are more similar to each other than Puerto Rico is to either the Bahamas or Florida without imposing any priors in a STRUCTURE analysis (MAF $\geq 0.05)$. However, it is not always possible to determine, with confidence, the correct clustering solution that accurately reflects genetic population structure when there is an underlying isolation by distance pattern (Frantz et al. 2009). We show here that there is significant isolation by geographic distance from Florida to the USVI when using presumably neutrally evolving SNP and microsatellite loci. Interestingly, inclusion of microsatellite locus 166, flagged as being an outlier locus, obscured this isolation by distance pattern (Supplemental Figure 8). Therefore, locus 166 is a strong candidate for a locus under selection (or it is linked to a locus under selection) and its functional significance might prove a fruitful subject for future studies (Nielsen et al. 2006). 
An east-west Caribbean divide was also evident in the corals Orbicella annularis (Foster

339

340

341

342

343

344

345

346

347

348

349

350

351

352

353

354

355

356

357

358

359

360

361

362

363

364

365

366

367

368

et al. 2012) and Acropora cervicornis (Vollmer \& Palumbi 2007). An additional barrier to gene flow in A. palmata was reported by Porto-Hannes et al. (2014) between Venezuela and the Mesoamerican Barrier Reef System utilizing four of the microsatellites markers.

The total number of SNPs $(n=307)$ retained for population genetic analysis was lower than expected. This was due to more than a 10 -fold increase in the number of fragments retrieved from the genome digest using the enzymes MluCI (^AATT) and NlaIII (CATG^) compared to what was predicted from an in-silico restriction of an incomplete draft genome of A. palmata (Baums, unpublished). The in-silico restriction predicted 19,067 to the actual $322,425($ read 1) and 276,753 (read 2) fragments retrieved. This under-prediction was most likely due to an early, incomplete genome draft and unknown genome size at the time of this study (Herrera et al. 2015). A larger set of SNP loci may reveal additional finer scale structure in A. palmata across the Caribbean. However, this may not necessarily be the case. In a study that used three orders of magnitude more loci (905,561 SNPs) failed to reveal population structure in A. digitifera collected from the Ryukyu Archipelago of Japan using Bayesian clustering based methods (Shinzato et al. 2015). Low coverage, 5X in this study, is also a concern however this depth of coverage has been used in other non-model species (Babbucci et al. 2016; Blanco-Bercial \& Bucklin 2016; Laporte et al. 2016). Yet, in the coral Platygyra daedalea, 5x coverage was sufficient to assign samples to two distinct clusters based on their geographic origin, the Persian Gulf or Sea of Oman and was consistent with their 20x coverage data set (Howells et al. 2016b).

A Mantel test showed a significant positive relationship between the SNP-derived pairwise $F_{S T}$ values and geographic distance $\left(r^{2}=0.65, p=0.05\right)$ consistent with the microsatellite results (10 loci) from the Florida, Bahamas, Puerto Rico, and Curacao samples (Fig4C, Fig4D). This may be due to Wright's Isolation-By-Distance (IBD) process however Mantel tests are prone to false positives as the test assumes spatial independence of the data (Meirmans 2012). Nevertheless, genetic variability is structured in geographic space.

Correlations between environmental factors including average temperature, salinity, dissolved oxygen, and pairwise $\mathrm{F}_{\mathrm{ST}}$ values or geographic distance were not significant (Fig4A, Fig4B). It should be noted that the environmental data had a resolution of $1 / 4$ to 1 degree latitude, an equivalent of about $28-111 \mathrm{~km}$, whereas the genetic data was collected on much smaller 
369 spatial scales. For example, in Florida, sampled reefs were often less than $10 \mathrm{~km}$ apart, and the

370 distance between Sand Island Reef and French Reef is only $2.6 \mathrm{~km}$. (Supplemental Table 2).

371 Here, reefs often harbor just one or a few A. palmata genets (albeit represented by many

372 colonies) making it challenging to obtain the needed $>25$ genets per population recommended for

$373 \mathrm{~F}_{\mathrm{ST}}$ analyses on a scale of a few $\mathrm{km}$. Thus, genets were pooled over geographic regions to match

374 the scale of the environmental data and yield sample sizes of at least 25 per location. Yet,

375 significant micro-environmental differences among colonies growing on the same reef have been

376 documented (Drury et al. 2017; Gorospe \& Karl 2010). Therefore, landscape genetic approaches

377 that may reveal environmental drivers of population differentiation (Manel et al. 2003) must

378 await higher resolution environmental data and, perhaps, a greater number of SNP loci.

\section{Genetic diversity indices in A. palmata}

380 Several factors could account for negative $\mathrm{F}_{\mathrm{IS}}$ values including negative assortative

381 mating, if a species is outcrossed and lacks selfed progeny or there is a selection pressure that

382 favors the most heterozygous genets. Of our samples, 49 out of 96 were ramets of larger genets.

383 A. palmata colonies fragment frequently; the branches regrow into new colonies resulting in

384

385

386

387

388

389

390

391

392

393

394

395

396

397

398

399

stands of genetically identical colonies (Baums et al. 2006a). [Note that samples included here all represented distinct genets]. Asexual reproduction could explain the excess of heterozygosity in A. palmata within the Florida region (see Balloux et al. 2003; Carlon 1999; Delmotte et al. 2002). Excess hetereozygosity has been observed in other clonal organisms. For example, significant negative $\mathrm{F}_{\mathrm{IS}}$ values in a partially clonal but self-incompatible wild cherry tree was explained in part by asexual reproduction (Stoeckel et al. 2006).

Nucleotide diversity is a measure of a species' genetic diversity and varies predictably with life history (Hamrick \& Godt 1996; Romiguier et al. 2014). Because A. palmata populations experienced dramatic losses in the 1980s and therefore may now have reduced genetic diversity we compared $A$. palmata's nucleotide diversity to the diversity found in other species. The nucleotide diversity $\pi$, describes the degree of nucleotide polymorphism in populations and can be calculated based on variant sites only or on variant and non-variant sites combined. In acroporids, estimates range from 0.007-0.022 (Macdonald et al. 2011) in A. austere to 0.09 in $A$. cervicornis (Drury et al. 2016). In other Cnidaria, estimates range from 0.00403 in Aiptasia (Bellis et al. 2016) to 0.0065 in Nematostella (Putnam et al. 2007). Synonymous nucleotide diversity ranged from $0.012-0.020$ in transcriptomes from three gorgonian species (Romiguier 
400

401

402

403

404

405

406

407

408

409

410

411

412

413

414

415

416

417

418

419

420

421

422

423

424

425

426

427

428

429

et al. 2014). Average pairwise nucleotide diversity in other metazoans include Drosophila pseudoobscura (0.0024-0.0179, Kulathinal et al. 2009) and Homo sapiens (0.000751, Sachidanandam et al. 2001). Our estimates of nucleotide diversity (including variant and nonvariant sites) was 0.0004 for all geographic regions, an order of magnitude lower than in other cnidarians. Further, based on a survey of 374 individual transcriptome-derived SNPs from 76 non-model animal species, the level of nucleotide diversity found in A. palmata is well below that predicted for a long-lived species, with small propagule size and large adult size (Romiguier et al. 2014). This low nucleotide diversity could be due to either a relatively small long-term effective population size, a severe bottleneck associated with a selective sweep (Ellegren \& Galtier 2016), the small number of SNPs included in this study (Fischer et al. 2017) or the RADtag method (Arnold et al. 2013). In addition, we find that Florida is the least genetically diverse geographic region when comparing nucleotide diversity in variant sites only $(0.203$, Table 3$)$, as would be expected in a marginal environment (Baums 2008; Baums et al. 2014a; Cahill \& Levinton 2016; Eckert et al. 2008). This is in contrast to Drury et. al, which found samples of the congener $A$. cervicornis from Florida to be higher in SNP nucleotide diversity than those from the Dominican Republic (Drury et al. 2016). Increased sampling of the genome as well as analysis of historical samples may shed light on whether the low nucleotide diversity in $A$. palmata is due to technical issues, the recent population bottleneck or unrelated causes.

Allelic richness of microsatellite data correlates better with genome-wide estimates of genetic diversity based on SNPs than heterozygosity (Fischer et al. 2017) and allelic richness is more sensitive to recent population bottlenecks than heterozygosity (Allendorf 1986). Average microsatellite-based allelic richness in 14 Indo-Pacific Acropora corals was 4.96 overall and 6.21 in the five geographically widespread species (calculated based on Table 6 in Richards \& Oppen 2012) which compares favorably with an average allelic richness of 8.49 in A. palmata found here. Thus, allelic richness of microsatellite loci remains high in Caribbean A. palmata despite recent population declines and the documented loss of alleles in Florida (Williams et al. 2014).

To resolve the contradictory findings with respect to genetic diversity based on micorsatellites and SNPs, future studies should include several thousand SNPs assayed in samples from across the species range. This approach may provide more conclusive data on the impact of recent population declines on overall genetic diversity in A. palmata. 
431 Genes under positive selection

432

433

434

435

436

437

438

439

440

441

442

443

444

445

446

447

448

449

450

451

452

453

454

455

456

457

458
Thirteen loci out of 395 were identified as being under positive selection in Acropora palmata. Detecting regions of the genome under selection is difficult, and statistical detection methods are prone to different rates of type 1 and type 2 errors. Further, LOSITAN and BAYESCAN often identify different loci as being under selection (Narum \& Hess 2011). LOSITAN identifies outliers based on the joint distributions of $\mathrm{F}_{\mathrm{ST}}$ and expected heterozygosity under an island model of migration (Beaumont \& Nichols 1996b). Whereas, BAYESCAN uses a hierarchical Bayesian method of Foll and Gaggiotti (2008), which has been modified based on the approach proposed by Beaumont and Balding (2004). Lotterhos et al claim that many of the published $\mathrm{F}_{\mathrm{ST}}$ outliers based on FDIST2 and BAYESCAN are probably false positives however, their results show that these false positives are mostly in balancing selection and we did not include outliers identified as being under balancing selection for this reason (Lotterhos \& Whitlock 2014). In a comparison of $\mathrm{F}_{\mathrm{ST}}$ outlier tests, FDIST2 and BAYESCAN appeared to provide the most power, depending on the scenario, and BAYESCAN had fewest false positives (Narum \& Hess 2011). Here, one locus 80994_17 (Digitifera scaffold gi|342271542|dbj|BACK01025553.1|, basepair = 5143) out of 13 was identified by both programs, therefore we consider this locus to be a strong candidate for being under selection and the other loci as possible candidates. However, STACKS locus 80994_17 was not annotated, a common occurrence even for transcribed loci in corals, where typically a third or less of genes have annotation (Meyer et al. 2011; Polato et al. 2010).

One of the SNP loci identified as being under positive selection was annotated as a tyrosine-protein kinase transmembrane receptor ROR1-like. ROR receptor protein is associated with the nervous system in the fruit fly Drosophila (Wilson et al. 1993), nematode C. elegans (Francis et al. 2005), and sea slug Aplysia californica (McKay et al. 2001). Functional analysis of cam-1, a gene that encodes for a ROR kinase in C. elegans, demonstrated roles in both the orientation of polarity in asymmetric cell division and axon outgrowth, and the ability to guide migrating cells (Forrester et al. 1999). The role of ROR1 receptors in Cnidaria is unknown although studies in Hydra suggest a function in regulating cell specification and tissue morphogenesis (Bertrand et al. 2014; Krishnapati \& Ghaskadbi 2014; Lange et al. 2014). 
Another SNP identified as being under positive selection was located in the gene

460

461

462

463

464

465

466

467

468

469

470

471

472

473

474

475

476

477

478

479

480

481

482

483

484

485

486

487

488

annotated as unconventional myosin-IXb isoform X7, a Rho GTPase-activating protein (RhoGAP) that is essential for coordinating the activity of Rho GTPases. Invertebrates are thought to contain a single myosin class IX gene (the exception is Drosphilia which has none) whereas most vertebrates have two with fishes having four (Liao et al. 2010). In general, Rho GTPases control the assembly and organization of the actin cytoskeleton which includes many functions such as cell adhesion, contraction and spreading, migration, morphogenesis, and phagocytosis. Little is known about the function of myosin-IX in invertebrates. However, a recent study in which Orbicella faveolata were exposed to immune challenges identified Unconventional myosin-IXb as a transcript that was significantly correlated with melanin protein activity (Fuess et al. 2016). In humans, Myosin-IXb is highly expressed in tissues of the immune system such as the lymph nodes, thymus, and spleen and also in imm cells like dendritic cells, macrophages and CD4 + T cells (Wirth et al. 1996). Myosin-IXb knockout mice showed impaired recruitment of monocytes and macrophages when exposed to a chemoattractant demonstrating that Myosin-IXb has an important function in innate immune responses in vivo (Hanley et al. 2010). Because statistical screens for loci under selection carry a high rate of false positive results, further experimental evidence is necessary before these loci can be considered targets of selection.

\section{Restoration implications}

Restoration efforts should proceed under the assumption that A. palmata harbors a significant amount of population structure requiring close matches of collection and outplant sites. Hybridization of $A$. palmata from different geographic regions may or may not result in heterosis depending on sexual compatibility, but would be worth pursuing in an ex situ setting to enable close monitoring of offspring performance under elevated temperatures (van Oppen et al. 2015). With respect to the sharply declining Florida colonies, these findings underline the need to manage and restore Florida's $A$. palmata as an isolated, genotypically depleted geographic region (Williams et al. 2014).

\section{Acknowledgements}

Thanks to PSU genome sequencing facility for expert library preparation and sequencing. $\mathrm{N}$ Polato contributed to the study design. We gratefully acknowledge the efforts by our 
489 collaborators around the Caribbean that have contributed samples over the years. This study was

490 funded by the National Atmospheric and Oceanic Administration (Award Number

491 NA13NOS4820029) and the National Science Foundation (OCE-1516763 and OCE-1537959) to 492 IBB. We thank the editor and three reviewers for insightful comments.

493

494 
495

496

497

498

499

500

501

502

503

504

505

506

507

508

509

510

511

512

513

514

515

516

517

518

519

520

521

522

523

524

\section{Figure legends}

Figure 1 Acropora palmata samples were obtained from throughout the Caribbean and northwest Atlantic range. Previous studies found a genetic break between the western and the eastern Caribbean but disagreed on the assignment of Puerto Rico to the western (long dashed line) or the eastern (short dashed line) population.

Figure 2 Bayesian cluster analysis of 307 SNP loci from Acropora palmata $(\mathrm{n}=96)$. Reefs within geographic regions 1-4 sorted by latitude: Florida, Bahamas, Puerto Rico, US Virgin Islands. Analysis included only one SNP per locus after combining Read 1 and Read 2. Shown is the probability of membership (y-axis) in a given cluster for each sample (x-axis) assuming values of $K=2(a), K=3$ (b), and $K=4$ (c). The most probable $K$ was 3 (b) for the minor allele frequency corrected SNPs based on the mean estimated log probability of the data at a given K (3 replicate runs per $\mathrm{K},+/-1$ standard deviation).

Figure 3 Bayesian cluster analysis of microsatellite data from Acropora palmata $(\mathrm{n}=260)$. Panels (a-c). Analysis of 11 microsatellite loci with the most probable K being 4. Panels (d-e). Exclusion of the outlier locus 166 resulted in the analysis of 10 microsatellites with the most probable $\mathrm{K}$ being 3. Shown is the probability of membership (y-axis) in a given cluster for each sample (x-axis) assuming values of $K=2(a, d), K=3(b, e)$, and $K=4$ (c, f).

Figure 4 MANTEL matrix correlation test between genetic $\left(\mathrm{F}_{\mathrm{st}}\right)$, environmental (Euclidean) and geographic distances $(\mathrm{km})$. . Acropora palmata samples from four geographic regions (Florida, Bahamas, Puerto Rico and USVI) were genotyped with 307 SNP (a-c) or 10 neutral microsatellite markers (d). Panel (a) $y=0.0107 x+0.0104, R^{2}=0.610, p=0.09$. Panel (b) $y=0.002 x+0.4175, R^{2}=0.101, p=0.21$. Panel (c) $y=0.000007 x+0.0098 . R^{2}=0.648, p-$ value $=0.05$. Panel $(d) y=0.000007 x+0.0027 . R^{2}=0.69, p=0.04$.

Supplemental Figure 1 SNP-derived $\mathrm{F}_{\mathrm{IS}}$ distribution of Acropora palmata in four geographic regions.

Supplemental Figure 2 SNP-derived $\mathrm{F}_{\mathrm{ST}}$ distributions of Acropora palmata in pairwise geographic region comparisons. Panel A: Bahamas vs Florida. Panel B: Bahamas vs Puerto Rico. 
525 Panel C: Bahamas vs USVI. Panel D: Florida vs Puerto Rico. Panel E: Florida vs USVI. Panel F:

526 Puerto Rico vs USVI.

527

528 Supplemental Figure 3 Minor allele frequency (MAF) cut of values of 0.025 (a-c) and 0.075 (d-

529 f) yield similar Bayesian population clustering solutions to MAF $=0.05$ (Fig 2 main text). Shown

530 is the probability of membership (y-axis) in a given cluster for each sample ( $\mathrm{x}$-axis) assuming

531 values of $K=2(a, d), K=3(b, e)$, and $K=4(c, f)$. For each $K$, three replicate runs were

532 performed. The most probable K was always 3 based on the mean estimated log probability of

533 the data at a given K and the Evanno method. Setting the minor allele frequency to 0.025 (a-c)

534 yields 632 SNPs (analysis included only one SNP per locus) after combining Read 1 and Read 2.

535 Setting the minor allele frequency to 0.075 (d-f) yields 213 SNPs (analysis included only one

536 SNP per locus) after combining Read 1 and Read 2. Reefs within geographic regions sorted by

537 latitude.

538

539 Supplemental Figure 4 Excluding $\mathrm{F}_{\mathrm{ST}}$ outliers from Acropora palmata SNP data does not

540 change the choice of best $\mathrm{K}$ based on Bayesian cluster analysis with STRUCTURE. Shown is the

541 probability of membership (y-axis) in a given cluster for each sample (x-axis) assuming values of

$542 \mathrm{~K}=2$ (a), $\mathrm{K}=3$ (b), and $\mathrm{K}=4$ (c). Analysis of 299 SNPs (analysis included only one SNP per

543 locus) after combining Read 1 and Read 2. The most probable K was 3 (B). Minor allele

544 frequency cut of value was 0.05 and percentage of missing data per geographic region was $40 \%$.

545 Reefs within geographic regions are sorted by latitude.

546

547 Supplemental Figure 5 Decreasing the minimum percentage of individuals in a region required

548 to have data for that locus from $60 \%$ to $40 \%$ does not change the choice of best $\mathrm{K}$ based on

549 Bayesian cluster analysis with STRUCTURE. Figure shows results of a STRUCTURE analysis of

5504793 SNPs (analysis included only one SNP per locus) after combining Read 1 and Read 2 and

551 assuming a $\mathrm{K}$ of 2 (A), 3 (B) or 4 (C). The minor allele frequency was set to $\geq 0.05$. The most

552 probable $\mathrm{K}$ was 3 (B) based on the mean estimated log probability of the data at a given $\mathrm{K}$ and

553 the Evanno method (3 replicate runs per $\mathrm{K},+/-1$ standard deviation). Reefs within geographic

554 regions are sorted by latitude.

555 
556 Supplemental Figure 6 Principal coordinate analysis (PCA) of single nucleotide polymorphism

557 (SNP, a) and microsatellite data (b) from Acropora palmata. Red= Florida, blue =Bahamas,

558 yellow $=$ Puerto Rico, green=USVI, purple=Belize, and orange $=$ Curacao .

559

560 Supplemental Figure 7 Cumulative distribution of sequencing coverage of Bowtie2 aligned

561 Acropora palmata reads to the $A$. digitifera genome using BEDTOOLS. On average 2.5\% percent

562 of the A. digitifera genome had sequence coverage at a stack depth of 5.

563

564 Supplemental Figure 8 Mantel matrix correlation test between genetic and geographic

565 distances. Acropora palmata samples from four geographic regions (Florida, Bahamas, Puerto

566 Rico and USVI) were genotyped with 11 microsatellite markers, including the outlier locus, 166.

$567 \mathrm{y}=5 * 10^{-6} \mathrm{x}+0.0137 . \mathrm{R}^{2}=0.1147, \mathrm{p}$-value $=0.1$. 
569 Tables

570

571 Table 1 Acropora palmata colonies included in the SNP (A) and microsatellite (B) analyses.

572 Samples were obtained from 3 - 6 (A) or more (B) reefs in four (A) and six (B) geographic

573 regions in the Caribbean/north-west Atlantic. Given are latitude and longitude in decimal degrees

574 (WGS84). NA = not available.

575 Table 2 RAD-tag sequencing summary table of Acropora palmata samples.

576 Table 3 Summary statistics for Read 1 and Read 2 combined. \% PL = percent polymorphic loci,

577 Obs Hom = observed homozygosity, Obs Het = observed heterozygosity, StdErr = standard

578 error, Exp = expected. $F_{I S}$ calculations with and without minor allele frequency restrictions.

579 Calculated by STACKS 1.30.

580 Table 4 Pairwise $F_{S T}$ calculated from STACKS 1.3. Read 1 and 2 combined (duplicated stacks

581 between reads removed, MAF $\geq 0.05)$. Considered were loci $(n=390)$ present in all geographic

582 regions.

583 Supplemental Table 1 DD-Rad sequencing. There were 12 pools with 8 unique barcodes in 584 each. The Database ID is a unique identifier for each coral specimen. Given is also the total 585 number of ramets for each genet in the Baumslab database. The indices are short DNA sequences 586 that uniquely identify products in the final libraries.

587 Supplemental Table 2 Example code for STACKS.

588 Supplemental Table 3 GPS coordinates in decimal degrees (WGS84) for the World Ocean 589 Atlas 2013 (WOA13 V2) environmental data, averaged for a geographic region.

590 Supplemental Table 4 Outlier SNPs identified by programs LOSITAN and BAYESCAN. Stacks 591 locus_bp is the STACKS program locus ID with the SNP location basepair after the underscore.

592 Read category indicates whether the outlier SNP was found in read 1 or read 2 or the paired-end 593 sequencing run. $A$. dig scaffold identifies the $A$. digitifera scaffold where the $A$. palmata STACKS 594 locus aligned to, followed by the basepair location in the next column. S start= sequence start. S 595 end $=$ sequence end. Lositan $\mathrm{P}=$ Lositan $\mathrm{P}$ - values $\left(\right.$ Simulated $\mathrm{F}_{\mathrm{ST}}<$ sample $\left.\mathrm{F}_{\mathrm{ST}}\right)$. Bayescan $\mathrm{q}=$ 596 Bayescan q-values. Ns = not significant. 597 
598

599 Supplemental Table 5 Microsatellite genotypes at five loci for the samples included in the SNP 600 dataset. The Database ID is a unique identifier for each coral specimen. Given is also is the 601 geographic region and reef the samples were collected from, microsatellite allele call 1 and 2 for 602 loci 166, 181, 182, 192, and 207 (in basebairs), and the coral genet ID. The last four columns 603 show how the radseq samples were pooled and gives the inline barcode, the Illumina index, the 604 Illumina sequence lane and chip.

605

606

607

608 
609

610

611

612

613

614

615

616

617

618

619

620

621

622

623

624

625

626

627

628

629

630

631

632

633

634

635

636

637

638

639

640

641

642

643

644

645

646

647

648

649

650

651

652

653

654

655
References

Allendorf FW. 1986. Genetic drift and the loss of alleles versus heterozygosity. Zoo Biology 5:181-190. 10.1002/zoo.1430050212

Altschul SF, Madden TL, Schäffer AA, Zhang J, Zhang Z, Miller W, and Lipman DJ. 1997. Gapped BLAST and PSI-BLAST: a new generation of protein database search programs. Nucleic acids research 25:3389-3402.

Altshuler D, Pollara VJ, Cowles CR, Van Etten WJ, Baldwin J, Linton L, and Lander ES. 2000. An SNP map of the human genome generated by reduced representation shotgun sequencing. Nature 407:513-516.

Antao T, Lopes A, Lopes RJ, Beja-Pereira A, and Luikart G. 2008. LOSITAN: A workbench to detect molecular adaptation based on a Fst-outlier method. Bmc Bioinformatics 9:323.

Arnold B, Corbett-Detig RB, HartI D, and Bomblies K. 2013. RADseq underestimates diversity and introduces genealogical biases due to nonrandom haplotype sampling. Molecular Ecology 22:3179-3190.

Babbucci M, Ferraresso S, Pauletto M, Franch R, Papetti C, Patarnello T, Carnier P, and Bargelloni L. 2016. An integrated genomic approach for the study of mandibular prognathism in the European seabass (Dicentrarchus labrax). Scientific reports 6 .

Balloux F, Lehmann L, and de Meeus T. 2003. The population genetics of clonal and partially clonal diploids. Genetics 164:1635-1644.

Baums IB. 2008. A restoration genetics guide for coral reef conservation. Molecular Ecology 17:27962811. doi:10.1111/j.1365-294X.2008.03787.x

Baums IB, Devlin-Durante M, Laing BA, Feingold J, Smith T, Bruckner A, and Monteiro J. 2014a. Marginal coral populations: the densest known aggregation of Pocillopora in the Galápagos Archipelago is of asexual origin. Frontiers in Marine Science 1:59.

Baums IB, Devlin-Durante MK, Brown L, and Pinzón JH. 2009. Nine novel, polymorphic microsatellite markers for the study of threatened Caribbean acroporid corals. Molecular Ecology Resources 9:1155-1158.

Baums IB, Devlin-Durante MK, and LaJeunesse TC. 2014b. New insights into the dynamics between reef corals and their associated dinoflagellate endosymbionts from population genetic studies. Molecular Ecology 23:4203-4215. 10.1111/mec.12788

Baums IB, Hughes CR, and Hellberg MH. 2005a. Mendelian microsatellite loci for the Caribbean coral Acropora palmata. Marine Ecology - Progress Series 288:115-127.

Baums IB, Johnson ME, Devlin-Durante MK, and Miller MW. 2010. Host population genetic structure and zooxanthellae diversity of two reef-building coral species along the Florida Reef Tract and wider Caribbean. Coral Reefs 29:835-842. 10.1007/s00338-010-0645-y

Baums IB, Miller MW, and Hellberg ME. 2005b. Regionally isolated populations of an imperiled Caribbean coral, Acropora palmata. Molecular Ecology 14:1377-1390.

Baums IB, Miller MW, and Hellberg ME. 2006a. Geographic variation in clonal structure in a reef building Caribbean coral, Acropora palmata. Ecological Monographs 76:503-519.

Baums IB, Paris CB, and Cherubin LM. 2006b. A bio-oceanographic filter to larval dispersal in a reefbuilding coral. Limnology and Oceanography 51:1969-1981.

Beaumont MA, and Balding DJ. 2004. Identifying adaptive genetic divergence among populations from genome scans. Molecular Ecology 13:969-980.

Beaumont MA, and Nichols RA. 1996a. Evaluating loci for use in the genetic analysis of population structure. Proceedings of the Royal Society of London Series B-Biological Sciences 263:16191626. 
656

657

658

659

660

661

662

663

664

665

666

667

668

669

670

671

672

673

674

675

676

677

678

679

680

681

682

683

684

685

686

687

688

689

690

691

692

693

694

695

696

697

698

699

700

701

702

Beaumont MA, and Nichols RA. 1996b. Evaluating loci for use in the genetic analysis of population structure. Proceedings of the Royal Society of London B: Biological Sciences 263:1619-1626.

Becks L, Ellner SP, Jones LE, and Hairston NG, Jr. 2010. Reduction of adaptive genetic diversity radically alters eco-evolutionary community dynamics. Ecology Letters 13:989-997. 10.1111/j.14610248.2010.01490.x

Bedoya-Reina O, Ratan A, Burhans R, Kim H, Giardine B, Riemer C, Li Q, Olson T, Loughran T, vonHoldt B, Perry G, Schuster S, and Miller W. 2013. Galaxy tools to study genome diversity. GigaScience 2:17.

Bellis ES, Howe DK, and Denver DR. 2016. Genome-wide polymorphism and signatures of selection in the symbiotic sea anemone Aiptasia. BMC Genomics 17:160.

Bertrand S, Iwema T, and Escriva H. 2014. FGF signaling emerged concomitantly with the origin of Eumetazoans. Molecular Biology and Evolution 31:310-318.

Blanco-Bercial L, and Bucklin A. 2016. New view of population genetics of zooplankton: RAD-seq analysis reveals population structure of the North Atlantic planktonic copepod Centropages typicus. Molecular Ecology 25:1566-1580.

Blankenberg D, Von Kuster G, Bouvier E, Baker D, Afgan E, Stoler N, Team G, Taylor J, and Nekrutenko A. 2014. Dissemination of scientific software with Galaxy ToolShed. Genome Biology 15:3. 10.1186/gb4161

Cahill AE, and Levinton JS. 2016. Genetic differentiation and reduced genetic diversity at the northern range edge of two species with different dispersal modes. Molecular Ecology 25:515-526.

Carlon DB. 1999. The evolution of mating systems in tropical reef corals. Trends in Ecology \& Evolution 14:491-495.

Catchen J, Hohenlohe PA, Bassham S, Amores A, and Cresko WA. 2013. Stacks: an analysis tool set for population genomics. Molecular Ecology 22:3124-3140. 10.1111/mec.12354

Catchen JM, Amores A, Hohenlohe P, Cresko W, and Postlethwait JH. 2011. Stacks: Building and Genotyping Loci De Novo From Short-Read Sequences. G3: Genes, Genomes, Genetics 1:171182. $10.1534 / g 3.111 .000240$

Combosch DJ, and Vollmer SV. 2015. Trans-Pacific RAD-Seq population genomics confirms introgressive hybridization in Eastern Pacific Pocillopora corals. Molecular phylogenetics and evolution 88:154-162.

Delmotte F, Leterme N, Gauthier JP, Rispe C, and Simon JC. 2002. Genetic architecture of sexual and asexual populations of the aphid Rhopalosiphum padi based on allozyme and microsatellite markers. Molecular Ecology 11:711-723. 10.1046/j.1365-294X.2002.01478.x

Dimond JL, Gamblewood SK, and Roberts SB. 2017. Genetic and epigenetic insight into morphospecies in a reef coral. Molecular Ecology.

Drury C, Dale KE, Panlilio JM, Miller SV, Lirman D, Larson EA, Bartels E, Crawford DL, and Oleksiak MF. 2016. Genomic variation among populations of threatened coral: Acropora cervicornis. Bmc Genomics 17:286. 10.1186/s12864-016-2583-8

Drury C, Manzello D, and Lirman D. 2017. Genotype and local environment dynamically influence growth, disturbance response and survivorship in the threatened coral, Acropora cervicornis. PLoS One 12:e0174000.

Eckert C, Samis K, and Lougheed S. 2008. Genetic variation across species' geographical ranges: the central-marginal hypothesis and beyond. Molecular Ecology 17:1170-1188.

Ellegren H, and Galtier N. 2016. Determinants of genetic diversity. Nature Reviews Genetics 17:422-433.

Epstein N, Bak RPM, and Rinkevich B. 2001. Strategies for Gardening Denuded Coral Reef Areas: The Applicability of Using Different Types of Coral Material for Reef Restoration. Restoration Ecology 9:432-442. 10.1046/j.1526-100X.2001.94012.x 
703

704

705

706

707

708

709

710

711

712

713

714

715

716

717

718

719

720

721

722

723

724

725

726

727

728

729

730

731

732

733

734

735

736

737

738

739

740

741

742

743

744

745

746

747

748

749
Evanno G, Regnaut S, and Goudet J. 2005. Detecting the number of clusters of individuals using the software STRUCTURE: a simulation study. Molecular Ecology 14:2611-2620.

Falush D, Stephens M, and Pritchard JK. 2003. Inference of population structure using multilocus genotype data: Linked loci and correlated allele frequencies. Genetics 164:1567-1587.

Fischer MC, Rellstab C, Leuzinger M, Roumet M, Gugerli F, Shimizu KK, Holderegger R, and Widmer A. 2017. Estimating genomic diversity and population differentiation - an empirical comparison of microsatellite and SNP variation in Arabidopsis halleri. Bmc Genomics 18:69. 10.1186/s12864016-3459-7

Fogarty ND. 2012. Caribbean acroporid coral hybrids are viable across life history stages. Marine Ecology Progress Series 446:145-159.

Foll M, and Gaggiotti O. 2008. A genome-scan method to identify selected loci appropriate for both dominant and codominant markers: a Bayesian perspective. Genetics 180:977-993.

Forrester WC, Dell M, Perens E, and Garriga G. 1999. A C. elegans Ror receptor tyrosine kinase regulates cell motility and asymmetric cell division. Nature 400:881-885.

Forsman Z, Knapp I, Tisthammer K, Eaton D, Belcaid M, and Toonen R. 2017. Coral hybridization or phenotypic variation? Genomic data reveal gene flow between Porites lobata and P. Compressa. Molecular phylogenetics and evolution 111:132-148.

Foster NL, Paris CB, Kool JT, Baums IB, Stevens JR, Sanchez JA, Bastidas C, Agudelo C, Bush P, Day O, Ferrari R, Gonzalez P, Gore S, Guppy R, McCartney MA, McCoy C, Mendes J, Srinivasan A, Steiner S, Vermeij MJA, Weil E, and Mumby PJ. 2012. Connectivity of Caribbean coral populations: complementary insights from empirical and modelled gene flow. Molecular Ecology 21:11431157. 10.1111/j.1365-294X.2012.05455.x

Francis MM, Evans SP, Jensen M, Madsen DM, Mancuso J, Norman KR, and Maricq AV. 2005. The Ror receptor tyrosine kinase CAM-1 is required for ACR-16-mediated synaptic transmission at the C. elegans neuromuscular junction. Neuron 46:581-594.

Frantz A, Cellina S, Krier A, Schley L, and Burke T. 2009. Using spatial Bayesian methods to determine the genetic structure of a continuously distributed population: clusters or isolation by distance? Journal of Applied Ecology 46:493-505.

Fuess LE, Weil E, and Mydlarz LD. 2016. Associations between transcriptional changes and protein phenotypes provide insights into immune regulation in corals. Developmental \& Comparative Immunology 62:17-28.

Gagnaire PA, Normandeau E, Cote C, Hansen MM, and Bernatchez L. 2012. The Genetic Consequences of Spatially Varying Selection in the Panmictic American Eel (Anguilla rostrata). Genetics 190:725-U703. 10.1534/genetics.111.134825

Gorospe KD, and Karl SA. 2010. Small-scale spatial analysis of in situ sea temperature throughout a single coral patch reef. Journal of Marine Biology 2011.

Griffin JN, Schrack EC, Lewis K-A, Baums IB, Soomdat N, and Silliman BR. 2015. Density-dependent effects on initial growth of a branching coral under restoration Restoration Ecology 23:197-200. 10.1111/rec.12173

Griffin S, Spathias H, Moore DM, Baums IB, and Griffin BA. 2012. Scaling up Acropora nurseries in the Caribbean and improving techniques. In: Yellowlees D, and Hughes TP, eds. Proceedings of the 12th International Coral Reef Symposium. Townsville, Australia: James Cook University.

Hamrick JL, and Godt M. 1996. Effects of life history traits on genetic diversity in plant species. Philosophical transactions: biological sciences:1291-1298.

Hanley PJ, Xu Y, Kronlage M, Grobe K, Schön P, Song J, Sorokin L, Schwab A, and Bähler M. 2010. Motorized RhoGAP myosin IXb (Myo9b) controls cell shape and motility. Proceedings of the National Academy of Sciences 107:12145-12150. 10.1073/pnas.0911986107 
750

Herrera S, Reyes-Herrera PH, and Shank TM. 2015. Predicting RAD-seq marker numbers across the eukaryotic tree of life. Genome biology and evolution 7:3207-3225.

Hoffberg SL, Kieran TJ, Catchen JM, Devault A, Faircloth BC, Mauricio R, and Glenn TC. 2016. RADcap: sequence capture of dual-digest RADseq libraries with identifiable duplicates and reduced missing data. Molecular Ecology Resources 16:1264-1278. 10.1111/1755-0998.12566

Howells EJ, Abrego D, Meyer E, Kirk NL, and Burt JA. 2016a. Host adaptation and unexpected symbiont partners enable reef-building corals to tolerate extreme temperatures. Global Change Biology 22:2702-2714. 10.1111/gcb.13250

Howells EJ, Abrego D, Meyer E, Kirk NL, and Burt JA. 2016b. Host adaptation and unexpected symbiont partners enable reef-building corals to tolerate extreme temperatures. Global change biology.

Hubisz M, Falush D, Stephens M, and Pritchard J. 2009. Inferring weak population structure with the assistance of sample group information. Molecular Ecology Resources 9:1322-1332.

Jeffreys H. 1961. The theory of probability. Oxford: Oxford University Press.

Jombart T. 2008. adegenet: a R package for the multivariate analysis of genetic markers. Bioinformatics 24:1403-1405.

Kopelman NM, Mayzel J, Jakobsson M, Rosenberg NA, and Mayrose I. 2015. Clumpak: a program for identifying clustering modes and packaging population structure inferences across K. Molecular ecology resources 15:1179-1191.

Krishnapati L-S, and Ghaskadbi S. 2014. Identification and characterization of VEGF and FGF from Hydra. International Journal of Developmental Biology 57:897-906.

Kulathinal RJ, Stevison LS, and Noor MA. 2009. The genomics of speciation in Drosophila: diversity, divergence, and introgression estimated using low-coverage genome sequencing. PLoS Genet 5:e1000550.

Lal MM, Southgate PC, Jerry DR, and Zenger KR. 2016. Fishing for divergence in a sea of connectivity: The utility of ddRADseq genotyping in a marine invertebrate, the black-lip pearl oyster Pinctada margaritifera. Marine genomics 25:57-68.

Lange E, Bertrand S, Holz O, Rebscher N, and Hassel M. 2014. Dynamic expression of a Hydra FGF at boundaries and termini. Development Genes and Evolution 224:235-244.

Langmead B, and Salzberg SL. 2012. Fast gapped-read alignment with Bowtie 2. Nature Methods 9:357U354. Doi 10.1038/Nmeth.1923

Laporte M, Pavey SA, Rougeux C, Pierron F, Lauzent M, Budzinski H, Labadie P, Geneste E, Couture P, and Baudrimont M. 2016. RAD sequencing reveals within-generation polygenic selection in response to anthropogenic organic and metal contamination in North Atlantic Eels. Molecular Ecology 25:219-237.

Liao W, Elfrink K, and Bähler M. 2010. Head of Myosin IX Binds Calmodulin and Moves Processively toward the Plus-end of Actin Filaments. Journal of Biological Chemistry 285:24933-24942. 10.1074/jbc.M110.101105

Lischer HEL, and Excoffier L. 2012. PGDSpider: an automated data conversion tool for connecting population genetics and genomics programs. Bioinformatics 28:298-299. 10.1093/bioinformatics/btr642

Lotterhos KE, and Whitlock MC. 2014. Evaluation of demographic history and neutral parameterization on the performance of FST outlier tests. Molecular Ecology 23:2178-2192.

Macdonald AH, Schleyer M, and Lamb J. 2011. Acropora austera connectivity in the south-western Indian Ocean assessed using nuclear intron sequence data. Marine Biology 158:613-621.

Manel S, Schwartz MK, Luikart G, and Taberlet P. 2003. Landscape genetics: combining landscape ecology and population genetics. Trends in Ecology \& Evolution 18:189-197. 
796

797

798

799

800

801

802

803

804

805

806

807

808

809

810

811

812

813

814

815

816

817

818

819

820

821

822

823

824

825

826

827

828

829

830

831

832

833

834

835

836

837

838

839

840

841

842

McKay SE, Hislop J, Scott D, Bulloch AG, Kaczmarek LK, Carew TJ, and Sossin WS. 2001. Aplysia ror forms clusters on the surface of identified neuroendocrine cells. Molecular and Cellular Neuroscience 17:821-841.

Mège P, Schizas NV, Garcia Reyes J, and Hrbek T. 2014. Genetic seascape of the threatened Caribbean elkhorn coral, Acropora palmata, on the Puerto Rico Shelf. Marine Ecology:online early. 10.1111/maec.12135

Meirmans PG. 2012. The trouble with isolation by distance. Molecular Ecology 21:2839-2846.

Meyer E, Aglyamova G, and Matz M. 2011. Profiling gene expression responses of coral larvae (Acropora millepora) to elevated temperature and settlement inducers using a novel RNA-Seq procedure. Molecular Ecology 20:3599-3616.

Morin PA, Martien KK, and Taylor BL. 2009. Assessing statistical power of SNPs for population structure and conservation studies. Molecular ecology resources 9:66-73. 10.1111/j.17550998.2008.02392.x

Narum SR, and Hess JE. 2011. Comparison of FST outlier tests for SNP loci under selection. Molecular ecology resources 11:184-194.

Nielsen EE, Hansen MM, and Meldrup D. 2006. Evidence of microsatellite hitch-hiking selection in Atlantic cod (Gadus morhua L.): implications for inferring population structure in nonmodel organisms. Molecular Ecology 15:3219-3229. 10.1111/j.1365-294X.2006.03025.x

Nosil P, Funk DJ, and Ortiz-Barrientos D. 2009. Divergent selection and heterogeneous genomic divergence. Molecular Ecology 18:375-402. DOI 10.1111/j.1365-294X.2008.03946.x

Peakall R, and Smouse PE. 2006. GENALEX 6: genetic analysis in Excel. Population genetic software for teaching and research. Molecular Ecology Notes 6:288-295.

Peterson BK, Weber JN, Kay EH, Fisher HS, and Hoekstra HE. 2012. Double Digest RADseq: An Inexpensive Method for De Novo SNP Discovery and Genotyping in Model and Non-Model Species. PLOS ONE 7. 10.1371/journal.pone.0037135

Polato NR, Voolstra CR, Schnetzer J, DeSalvo MK, Randall CJ, Szmant AM, Medina M, and Baums IB. 2010. Location-specific responses to thermal stress in larvae of the reef-building coral Montastraea faveolata. PLoS One 5:e11221. 10.1371/journal.pone.0011221

Porto-Hannes I, Zubillaga AL, Shearer TL, Bastidas C, Salazar C, Coffroth MA, and Szmant AM. 2014. Population structure of the corals Orbicella faveolata and Acropora palmata in the Mesoamerican Barrier Reef System with comparisons over Caribbean basin-wide spatial scale. Marine Biology:1-18. 10.1007/s00227-014-2560-1

Putnam NH, Srivastava M, Hellsten U, Dirks B, Chapman J, Salamov A, Terry A, Shapiro H, Lindquist E, and Kapitonov VV. 2007. Sea anemone genome reveals ancestral eumetazoan gene repertoire and genomic organization. Science 317:86-94.

Quinlan AR, and Hall IM. 2010. BEDTools: a flexible suite of utilities for comparing genomic features. Bioinformatics 26:841-842. 10.1093/bioinformatics/btq033

Reitzel AM, Herrera S, Layden MJ, Martindale MQ, and Shank TM. 2013. Going where traditional markers have not gone before: utility of and promise for RAD sequencing in marine invertebrate phylogeography and population genomics. Molecular Ecology 22:2953-2970. 10.1111/mec.12228

Renaut S, Nolte AW, Rogers SM, Derome N, and Bernatchez L. 2011. SNP signatures of selection on standing genetic variation and their association with adaptive phenotypes along gradients of ecological speciation in lake whitefish species pairs (Coregonus spp.). Molecular Ecology 20:545559.

Richards ZT, and Oppen MJH. 2012. Rarity and genetic diversity in Indo-Pacific Acropora corals. Ecology and Evolution 2:1867-1888. 10.1002/ece3.304 
843

844

845

846

847

848

849

850

851

852

853

854

855

856

857

858

859

860

861

862

863

864

865

866

867

868

869

870

871

872

873

874

875

876

877

878

879

880

881

882

883

884

885

886

887

888

Rinkevich B. 2006. The coral gardening concept and the use of underwater nurseries: lessons learned from silvics and silviculture. Coral reef restoration handbook:291-302.

Romiguier J, Gayral P, Ballenghien M, Bernard A, Cahais V, Chenuil A, Chiari Y, Dernat R, Duret L, and Faivre N. 2014. Comparative population genomics in animals uncovers the determinants of genetic diversity. Nature 515:261.

Ryman N, Palm S, Andre C, Carvalho GR, Dahlgren TG, Jorde PE, Laikre L, Larsson LC, Palme A, and Ruzzante DE. 2006. Power for detecting genetic divergence: differences between statistical methods and marker loci. Molecular Ecology 15:2031-2045.

Sachidanandam R, Weissman D, Schmidt SC, Kakol JM, Stein LD, Marth G, Sherry S, Mullikin JC, Mortimore BJ, and Willey DL. 2001. A map of human genome sequence variation containing 1.42 million single nucleotide polymorphisms. Nature 409:928-933.

Schopmeyer SA, Lirman D, Bartels E, Byrne J, Gilliam DS, Hunt J, Johnson ME, Larson EA, Maxwell K, Nedimyer K, and Walter C. 2012. In Situ Coral Nurseries Serve as Genetic Repositories for Coral Reef Restoration after an Extreme Cold-Water Event. Restoration Ecology 20:696-703. 10.1111/j.1526-100X.2011.00836.x

Selkoe KA, and Toonen RJ. 2011. Marine connectivity: a new look at pelagic larval duration and genetic metrics of dispersal. Marine Ecology Progress Series 436:291-305. 10.3354/meps09238

Shinzato C, Mungpakdee S, Arakaki N, and Satoh N. 2015. Genome-wide SNP analysis explains coral diversity and recovery in the Ryukyu Archipelago. Scientific reports 5:18211.

Shinzato C, Shoguchi E, Kawashima T, Hamada M, Hisata K, Tanaka M, Fujie M, Fujiwara M, Koyanagi R, Ikuta T, Fujiyama A, Miller DJ, and Satoh N. 2011. Using the Acropora digitifera genome to understand coral responses to environmental change. Nature 476:320-323. 10.1038/nature10249

Sork VL, Squire K, Gugger PF, Steele SE, Levy ED, and Eckert AJ. 2016. Landscape genomic analysis of candidate genes for climate adaptation in a California endemic oak, Quercus lobata. American Journal of Botany 103:33-46. 10.3732/ajb.1500162

Stoeckel S, Grange J, Fernandez-Manjarres JF, Bilger I, Frascaria-Lacoste N, and Mariette S. 2006. Heterozygote excess in a self-incompatible and partially clonal forest tree species - Prunus avium L. Molecular Ecology 15:2109-2118. 10.1111/j.1365-294X.2006.02926.x

Toonen RJ, Puritz JB, Forsman ZH, Whitney JL, Fernandez-Silva I, Andrews KR, and Bird CE. 2013. ezRAD: a simplified method for genomic genotyping in non-model organisms. PeerJ 1:e203. 10.7717/peerj.203

van Oppen MJH, Oliver JK, Putnam HM, and Gates RD. 2015. Building coral reef resilience through assisted evolution. Proceedings of the National Academy of Sciences 112:2307-2313. 10.1073/pnas.1422301112

Vasemägi A, Nilsson J, and Primmer CR. 2005. Expressed Sequence Tag-Linked Microsatellites as a Source of Gene-Associated Polymorphisms for Detecting Signatures of Divergent Selection in Atlantic Salmon (Salmo salar L.). Molecular Biology and Evolution 22:1067-1076. 10.1093/molbev/msi093

Vilas A, PÉRez-Figueroa A, and Caballero A. 2012. A simulation study on the performance of differentiation-based methods to detect selected loci using linked neutral markers. Journal of evolutionary biology 25:1364-1376. 10.1111/j.1420-9101.2012.02526.x

Vollmer SV, and Palumbi SR. 2007. Restricted gene flow in the Caribbean staghorn coral Acropora cervicomis: Implications for the recovery of endangered reefs. Journal of Heredity 98:40-50.

Wang S, Meyer E, McKay JK, and Matz MV. 2012. 2b-RAD: a simple and flexible method for genomewide genotyping. Nature Methods 9:808-+. 10.1038/nmeth.2023 
889 Williams DE, Miller MW, and Baums IB. 2014. Cryptic changes in the genetic structure of a highly clonal coral population and the relationship with ecological performance. Coral Reefs 33:595-606.

891

892

893

894

895

896

897

898

899 10.1007/s00338-014-1157-y

Willing E-M, Dreyer C, and van Oosterhout C. 2012. Estimates of Genetic Differentiation Measured by F(ST) Do Not Necessarily Require Large Sample Sizes When Using Many SNP Markers. PLoS One 7:e42649. 10.1371/journal.pone.0042649

Wilson C, Goberdhan D, and Steller H. 1993. Dror, a potential neurotrophic receptor gene, encodes a Drosophila homolog of the vertebrate Ror family of Trk-related receptor tyrosine kinases. Proceedings of the National Academy of Sciences 90:7109-7113.

Wirth J, Jensen K, Post P, Bement W, and Mooseker M. 1996. Human myosin-IXb, an unconventional myosin with a chimerin-like rho/rac GTPase-activating protein domain in its tail. Journal of Cell

900 Science 109:653-661.

901

902 
903

904

905

906

907

908

909

\begin{tabular}{|c|c|c|c|c|}
\hline Region & Reef & $\begin{array}{l}\text { Count of } \\
\text { Samples }\end{array}$ & Latitude & Longitude \\
\hline \multirow[t]{5}{*}{ Florida } & Sand Island & 6 & 25.018093 & -80.368472 \\
\hline & French & 8 & 25.03393 & -80.34941 \\
\hline & Little Grecian & 1 & 25.118433 & -80.31715 \\
\hline & Horseshoe & 1 & 25.139467 & -80.29435 \\
\hline & Elbow & 8 & 25.143628 & -80.257927 \\
\hline \multirow[t]{6}{*}{ Bahamas } & Little Ragged Island & 1 & 22.15375 & -75.687208 \\
\hline & Adelaine Cay & 8 & 22.173372 & -75.703016 \\
\hline & Elkhorn Cay & 2 & 22.328253 & -75.783228 \\
\hline & Johnson Cay & 3 & 22.33312 & -75.77892 \\
\hline & Nairn Cay & 8 & 22.35199 & -75.79612 \\
\hline & Middle Beach & 2 & 23.781199 & -76.10391 \\
\hline \multirow[t]{4}{*}{ Puerto Rico } & San Cristobal & 8 & 17.56493 & -67.04515 \\
\hline & Rincon & 6 & 18.21007 & -67.15849 \\
\hline & Tres Palmas & 2 & 18.350133 & -67.266333 \\
\hline & La Cordillera & 8 & 18.368522 & -65.571678 \\
\hline \multirow{3}{*}{$\begin{array}{r}\text { US Virgin } \\
\text { Islands }\end{array}$} & Tague Bay & 8 & 17.763867 & -64.613397 \\
\hline & Hawksnest Bay & 8 & 18.347183 & -64.780775 \\
\hline & Johnsons Reef & 8 & 18.361733 & -64.7743 \\
\hline Grand Total & & 96 & & \\
\hline
\end{tabular}

910

911 B)

912

Table 1 Acropora palmata colonies included in the SNP (A) and microsatellite (B) analyses.

Samples were obtained from 3-6 (A) or more (B) reefs in four (A) and six (B) geographic regions in the Caribbean/north-west Atlantic. Given are latitude and longitude in decimal degrees (WGS84). NA = not available.

A)

Grand Total

\begin{tabular}{|l|l|l|l|l|}
\hline \multirow{4}{*}{ Region } & Reef & $\begin{array}{l}\text { Count of } \\
\text { Samples }\end{array}$ & Latitude & Longitude \\
\hline \multirow{5}{*}{ Florida } & Horseshoe & 1 & 25.1395 & -80.294 \\
\cline { 2 - 5 } & Little Grecian & 1 & 25.1184 & -80.317 \\
\cline { 2 - 5 } & Sand Island & 6 & 25.0179 & -80.369 \\
\cline { 2 - 5 } & Western Sambo & 6 & 24.4799 & -81.719 \\
\cline { 2 - 5 } & Rock Key & 4 & 24.456 & -81.86 \\
\cline { 2 - 5 } & Dry Tortugas & 1 & 24.6209 & -82.868 \\
\cline { 2 - 5 } & Marker 3 & 1 & 25.3733 & -80.16 \\
\hline
\end{tabular}




\begin{tabular}{|c|c|c|c|c|}
\hline Region & Reef & $\begin{array}{l}\text { Count of } \\
\text { Samples }\end{array}$ & Latitude & Longitude \\
\hline & Boomerang Reef & 1 & 25.3525 & -80.179 \\
\hline & Carysfort & 4 & 25.2219 & -80.211 \\
\hline \multirow{13}{*}{ Bahamas } & Great Iguana & 19 & 26.7075 & -77.154 \\
\hline & Middle Beach & 2 & 23.7812 & -76.104 \\
\hline & Charlies Beach & 1 & 23.7808 & -76.104 \\
\hline & Black Bouy & 1 & 23.8022 & -76.146 \\
\hline & Bock Cay & 1 & 23.8075 & -76.16 \\
\hline & Little Darby & 2 & 23.8474 & -76.209 \\
\hline & Rocky Dundas & 1 & 24.2788 & -76.539 \\
\hline & Halls Pond & 2 & 24.3539 & -76.57 \\
\hline & LSI & 3 & 23.7691 & -76.096 \\
\hline & Little Ragged Island & 1 & 22.1538 & -75.687 \\
\hline & Adelaine Cay & 1 & 22.1734 & -75.703 \\
\hline & Johnson Cay & 1 & 22.3331 & -75.779 \\
\hline & Nairn Cay & 4 & 22.352 & -75.796 \\
\hline \multirow{4}{*}{$\begin{array}{l}\text { Puerto } \\
\text { Rico }\end{array}$} & San Cristobal & 14 & 17.5649 & -67.045 \\
\hline & Rincon & 24 & 18.2101 & -67.159 \\
\hline & Aurora & 3 & 17.9425 & -66.871 \\
\hline & Paraguera & 1 & 17.997 & -67.052 \\
\hline \multirow{8}{*}{$U S V I$} & Hawksnest Bay & 6 & 18.3472 & -64.781 \\
\hline & Johnsons Reef & 12 & 18.3617 & -64.774 \\
\hline & Haulover Bay & 13 & 18.3489 & -64.677 \\
\hline & Buck Island & 14 & 18.2774 & -64.894 \\
\hline & Flat Key & 4 & 18.317 & -64.989 \\
\hline & Hans Lollik & 4 & 18.4019 & -64.906 \\
\hline & Sapphire & 6 & 18.3333 & -64.85 \\
\hline & Botany & 3 & 18.3572 & -65.036 \\
\hline \multirow{10}{*}{ Belize } & unknown & 3 & NA & NA \\
\hline & Bugle Caye & 1 & NA & NA \\
\hline & Curlew & 5 & 16.7909 & -88.083 \\
\hline & Gladden & 1 & 16.4401 & -88.192 \\
\hline & Glovers Atoll & 3 & NA & NA \\
\hline & GSTF1 & 5 & 16.5499 & -88.05 \\
\hline & GSTF12 & 7 & 16.5499 & -88.05 \\
\hline & Larks Caye & 1 & NA & NA \\
\hline & Laughing Bird Caye & 4 & 16.4367 & -88.199 \\
\hline & Loggerhead & 2 & NA & NA \\
\hline
\end{tabular}




\begin{tabular}{|l|l|l|l|l|}
\hline \multirow{4}{*}{ Region } & Reef & $\begin{array}{l}\text { Count of } \\
\text { Samples }\end{array}$ & Latitude & Longitude \\
\hline \multirow{5}{*}{ Curacao } & Sandbores & 3 & 16.7791 & -88.118 \\
\cline { 2 - 5 } & Carrie Bow & 13 & 16.8021 & -88.082 \\
\cline { 2 - 5 } & Blue Bay & 7 & 12.1352 & -68.99 \\
\cline { 2 - 5 } & Boka Patrick & 8 & 12.2873 & -69.043 \\
\cline { 2 - 5 } & Directors Bay & 2 & 12.0664 & -68.8603 \\
\cline { 2 - 5 } & East Point & 4 & 12.0407 & -68.783 \\
\cline { 2 - 5 } & PuntuPicu & 9 & 12.0831 & -68.896 \\
\cline { 2 - 5 } & Red Bay & 2 & 12.1355 & -68.99 \\
\cline { 2 - 5 } & Sea Aquarium & 9 & 12.0838 & -68.896 \\
\cline { 2 - 5 } & Water Factory & 3 & & \\
\hline \multirow{5}{*}{ Sum } & & 260 & & \\
\hline
\end{tabular}


915

916 Table 2 RAD-tag sequencing summary table of Acropora palmata samples.

917

\begin{tabular}{|c|c|c|c|c|c|c|c|c|}
\hline & Region & Pool & $\begin{array}{l}\text { Coral } \\
\text { colonies }\end{array}$ & Lane & Total Reads & $\begin{array}{l}\text { Retained } \\
\text { Reads after } \\
\text { processing }\end{array}$ & $\begin{array}{l}\text { Average } \\
\text { number of } \\
\text { retained } \\
\text { sequence } \\
\text { reads per } \\
\text { sample }\end{array}$ & $\begin{array}{l}\text { Standard } \\
\text { Deviation }\end{array}$ \\
\hline \multirow[t]{6}{*}{ West } & \multirow[t]{3}{*}{ Bahamas } & B1 & 8 & 2 & $50,900,230$ & $41,199,646$ & $5,149,956$ & $1,915,875$ \\
\hline & & B2 & 8 & 2 & $56,097,984$ & $45,237,633$ & $5,654,704$ & $1,853,265$ \\
\hline & & B3 & 8 & 2 & $58,379,852$ & $47,706,860$ & $5,963,358$ & $2,734,261$ \\
\hline & \multirow[t]{3}{*}{ Florida } & $\mathrm{F} 1$ & 8 & 1 & $50,925,548$ & $39,750,070$ & $4,968,759$ & $1,681,820$ \\
\hline & & $\mathrm{F} 2$ & 8 & 1 & $48,752,776$ & $42,036,153$ & $5,254,519$ & $4,422,737$ \\
\hline & & F3 & 8 & 1 & $49,942,322$ & $38,611,895$ & $4,826,487$ & $2,518,097$ \\
\hline \multirow[t]{7}{*}{ East } & \multirow{3}{*}{$\begin{array}{l}\text { Puerto } \\
\text { Rico }\end{array}$} & $\mathrm{P} 1$ & 8 & 1 & $43,979,338$ & $36,237,997$ & $4,529,750$ & $4,166,551$ \\
\hline & & $\mathrm{P} 2$ & 8 & 1 & $55,267,402$ & $47,235,081$ & $5,904,385$ & $4,096,287$ \\
\hline & & P3 & 8 & 1 & $47,324,190$ & $34,835,445$ & $4,354,431$ & $3,117,707$ \\
\hline & \multirow[t]{3}{*}{ USVI } & U1 & 8 & 2 & $40,616,766$ & $33,170,324$ & $4,146,291$ & $2,187,597$ \\
\hline & & $\mathrm{U} 2$ & 8 & 2 & $43,215,386$ & $34,291,498$ & $4,286,437$ & $1,187,166$ \\
\hline & & U3 & 8 & 2 & $45,849,098$ & $38,439,719$ & $4,804,965$ & $1,555,938$ \\
\hline & & Sum & 96 & & $591,250,892$ & $478,752,321$ & & \\
\hline
\end{tabular}


919 Table 3 Summary statistics for Read 1 and Read 2 combined. \% PL = percent polymorphic loci, 920 Obs Hom = observed homozygosity, Obs Het = observed heterozygosity, StdErr = standard 921 error, Exp = expected. $F_{I S}$ calculations with and without minor allele frequency restrictions.

922 Calculated by STACKS 1.30.

923

\begin{tabular}{|c|c|c|c|c|c|}
\hline & & Bahamas & Florida & Puerto Rico & USVI \\
\hline \multirow{6}{*}{$\begin{array}{l}\text { All } \\
\text { positions: } \\
\text { variant and } \\
\text { fixed }\end{array}$} & Total Sites & 200425 & 200425 & 200425 & 200425 \\
\hline & Variant Sites & 390 & 390 & 390 & 390 \\
\hline & $\begin{array}{l}\text { Private } \\
\text { Alleles }\end{array}$ & 2 & 1 & 0 & 2 \\
\hline & $\% \mathrm{PL}$ & 0.1732 & 0.1497 & 0.1694 & 0.1668 \\
\hline & $\mathrm{F}_{\mathrm{IS}}$ & 0.00005 & 0 & 0 & 0.00005 \\
\hline & $\begin{array}{l}\text { Nucleotide } \\
\text { diversity }(\pi)\end{array}$ & 0.0004 & 0.0004 & 0.0004 & 0.0004 \\
\hline \multirow{8}{*}{$\begin{array}{l}\text { Variant } \\
\text { positions } \\
\text { only }\end{array}$} & Obs Hom & 0.7728 & 0.7874 & 0.7791 & 0.7815 \\
\hline & Std Err & 0.0164 & 0.0164 & 0.0154 & 0.0154 \\
\hline & Obs Het & 0.2273 & 0.2126 & 0.2210 & 0.2186 \\
\hline & Std Err & 0.0164 & 0.0164 & 0.0154 & 0.0154 \\
\hline & Exp Hom & 0.7832 & 0.8050 & 0.7919 & 0.7916 \\
\hline & Exp Het & 0.2169 & 0.1951 & 0.2081 & 0.2085 \\
\hline & $\mathrm{F}_{\mathrm{IS}}$ & 0.02235 & -0.0086 & 0.0035 & 0.02065 \\
\hline & $\begin{array}{l}\text { Nucleotide } \\
\text { diversity }(\pi)\end{array}$ & 0.2254 & 0.2034 & 0.2174 & 0.21705 \\
\hline
\end{tabular}


926

927 Table 4 Pairwise $F_{S T}$ comparisons of geographic regions based on SNP (A) and microsatellite 928 (B) data.

$929 \quad$ A)

\begin{tabular}{|l|l|l|l|l|}
\hline & Bahamas & Florida & $\begin{array}{l}\text { Puerto } \\
\text { Rico }\end{array}$ & USVI \\
\hline Bahamas & & & & \\
\hline Florida & 0.018 & & & \\
\hline Puerto Rico & 0.013 & 0.022 & & \\
\hline USVI & 0.018 & 0.022 & 0.009 & \\
\hline
\end{tabular}

930

931

932

B)

\begin{tabular}{|l|l|l|l|l|l|l|}
\hline & Belize & Florida & Bahamas & Puerto Rico & USVI & Curacao \\
\hline Belize & & & & & & \\
\hline Florida & 0.0040 & & & & & \\
\hline Bahamas & 0.0115 & 0.0097 & & & & \\
\hline Puerto Rico & 0.0206 & 0.0153 & 0.0063 & & & \\
\hline USVI & 0.0206 & 0.0174 & 0.0098 & 0.0037 & & \\
\hline Curacao & 0.0240 & 0.0138 & 0.0181 & 0.0173 & 0.0208 & \\
\hline
\end{tabular}




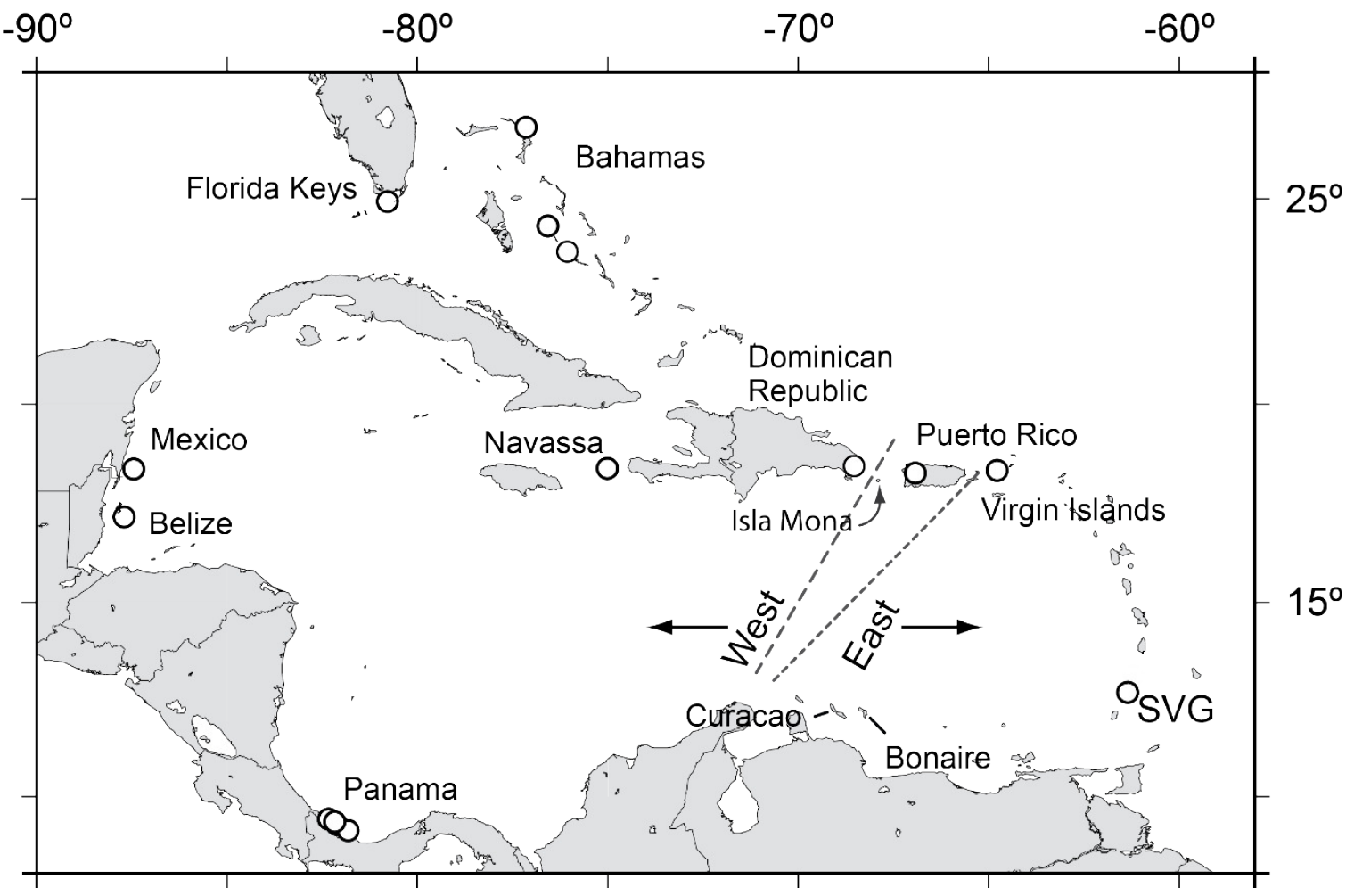

Figure 1 Acropora palmata samples were obtained from throughout the Caribbean and north-west Atlantic range. Previous studies found a genetic break between the western and the eastern Caribbean but disagreed on the assignment of Puerto Rico to the western (long dashed line) or the eastern (short dashed line) population. 

a) $\mathrm{K}=2$
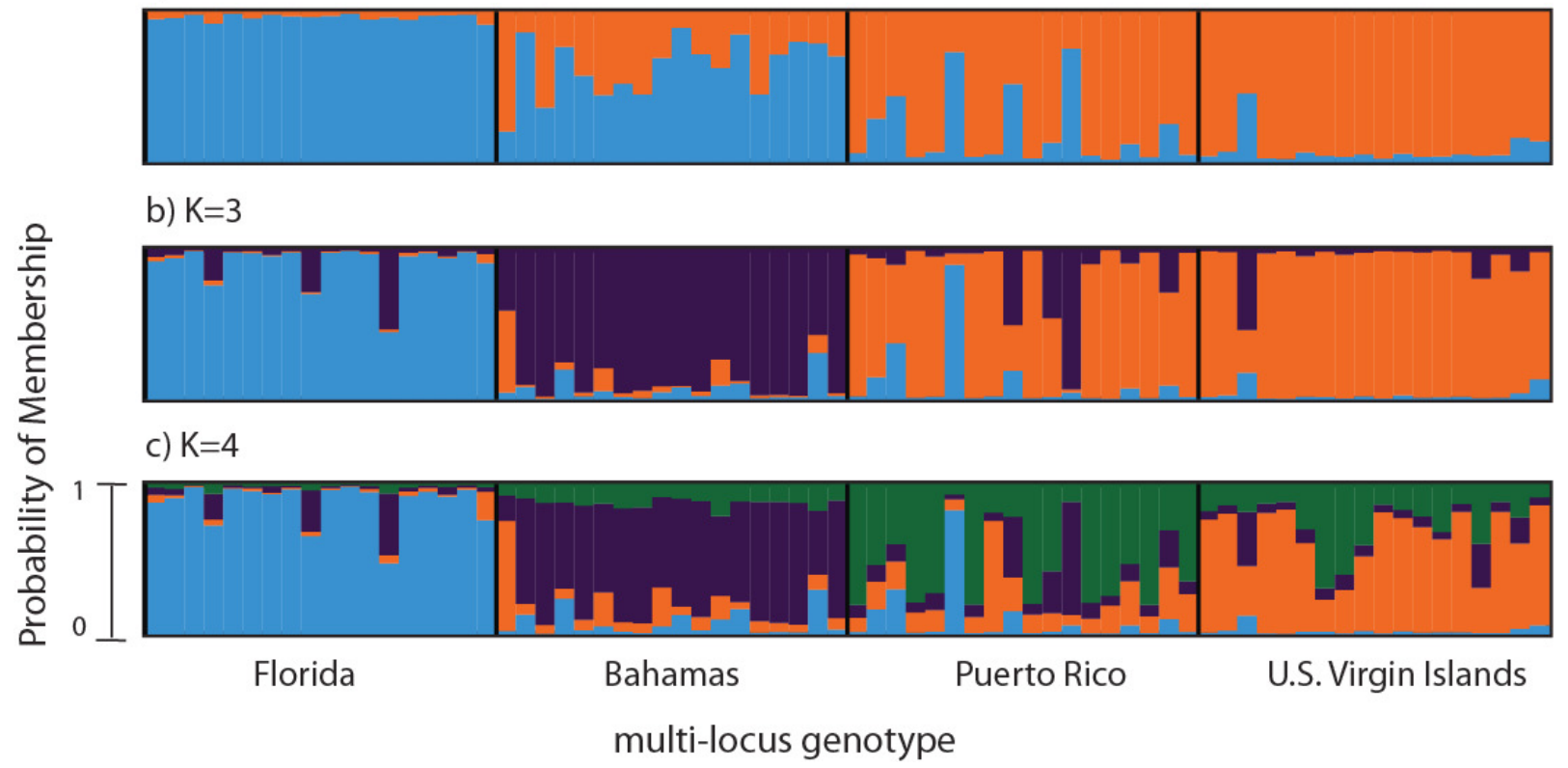

Figure 2 Bayesian cluster analysis of 307 SNP loci from Acropora palmata $(\mathrm{n}=96)$. Reefs within geographic regions 1-4 sorted by latitude: Florida, Bahamas, Puerto Rico, US Virgin Islands. Analysis included only one SNP per locus after combining Read 1 and Read 2. Shown is the probability of membership (y-axis) in a given cluster for each sample (x-axis) assuming values of $K=2$ (a), $K=3$ (b), and $K=4$ (c). The most probable K was 3 (b) for the minor allele frequency corrected SNPs based on the mean estimated log probability of the data at a given $\mathrm{K}$ ( 3 replicate runs per $\mathrm{K}$, +/- 1 standard deviation). 
a) $\mathrm{K}=2$

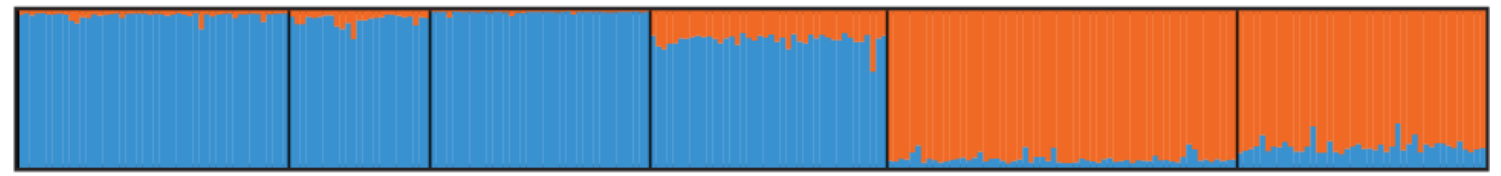

b) $\mathrm{K}=3$

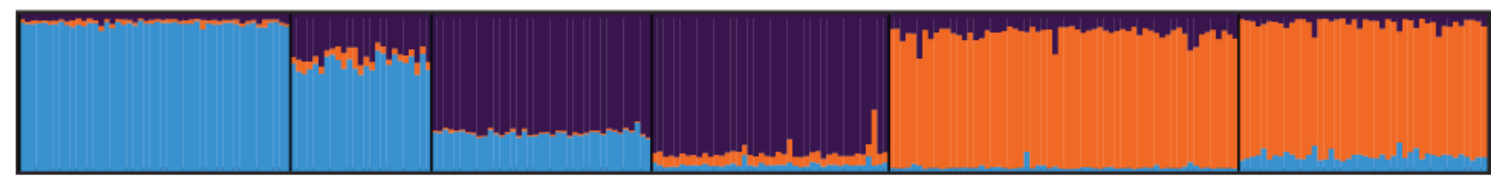

c) $\mathrm{K}=4$

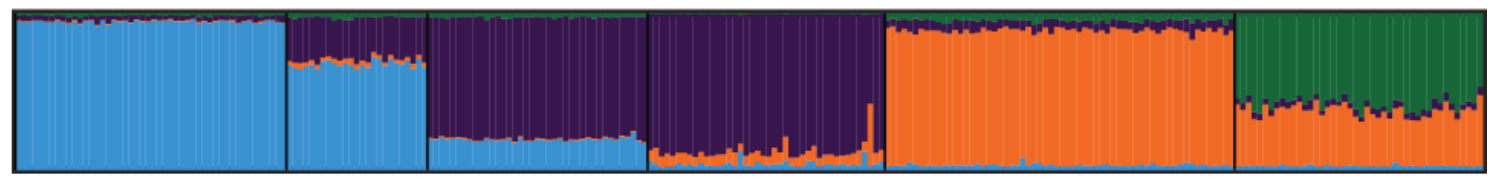

d) $\mathrm{K}=2$

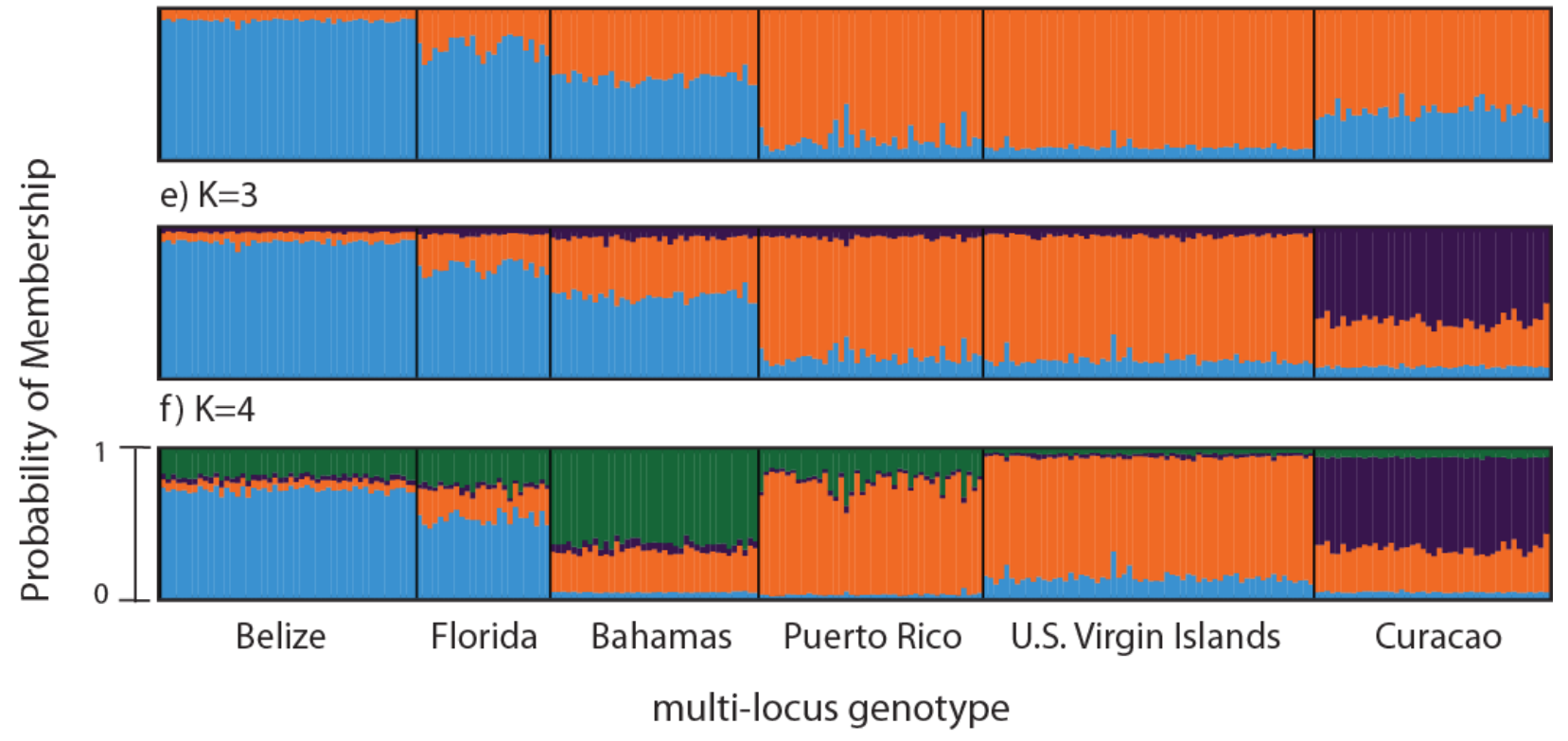

Figure 3 Bayesian cluster analysis of microsatellite data from Acropora palmata $(\mathrm{n}=260)$. Panels (a-c): Analysis of 11 microsatellite loci with the most probable K being 4. Panels (d-e): Exclusion of the outlier locus 166 resulted in the analysis of 10 microsatellites with the most probable $\mathrm{K}$ being 3. Shown is the probability of membership (y-axis) in a given cluster for each sample (x-axis) assuming values of $K=2(a, d), K=3(b, e)$, and $K=4(c, f)$. 
A

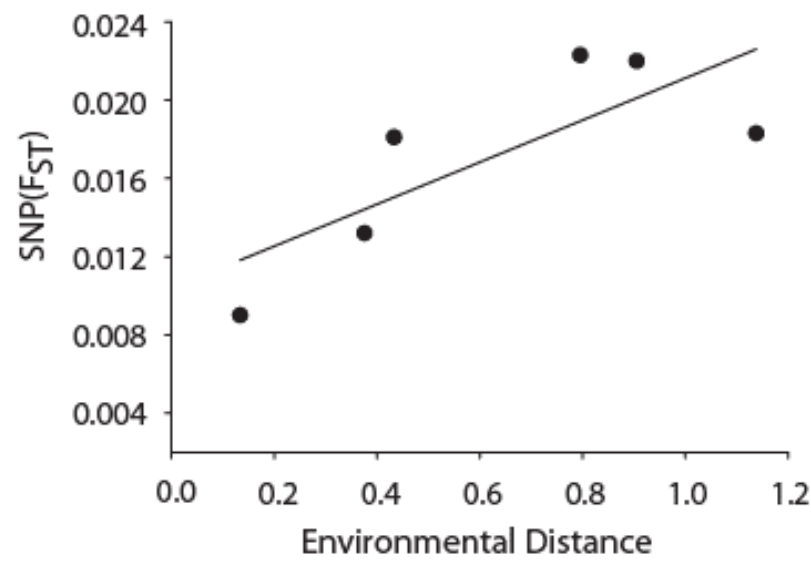

C

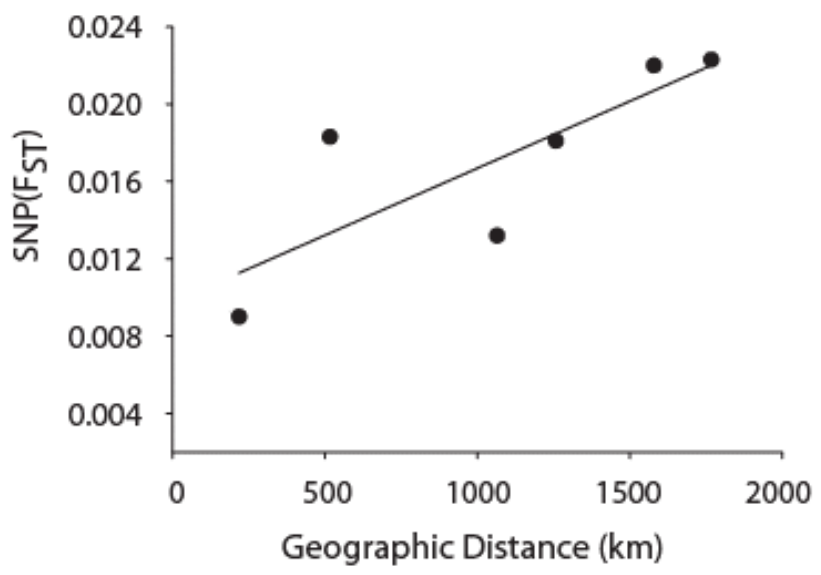

B

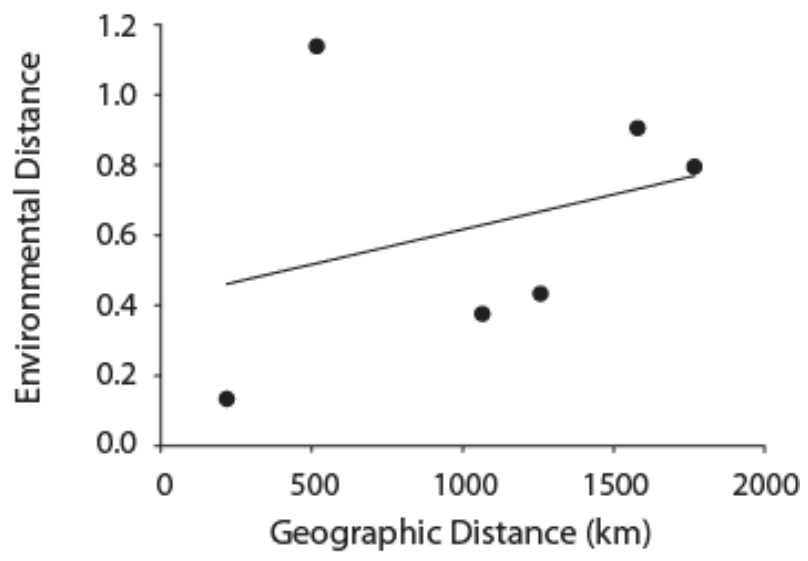

D

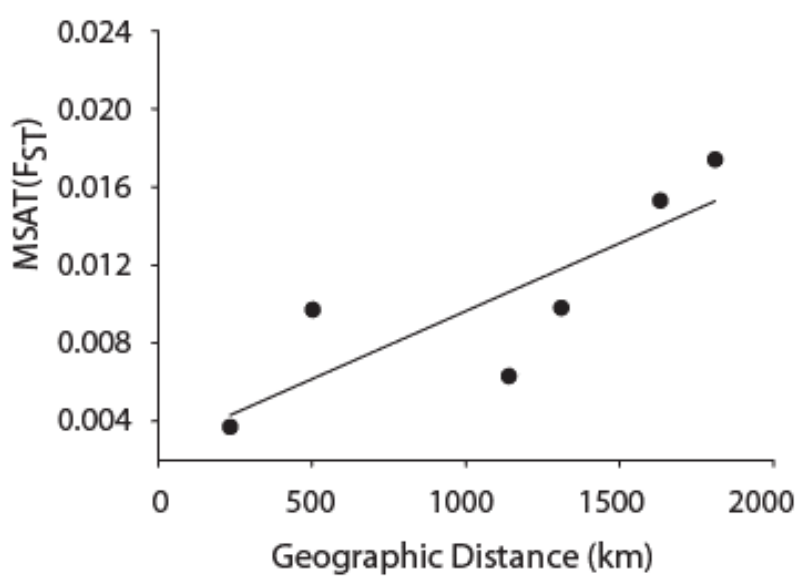

Figure 4 MANTEL matrix correlation test between genetic and geographic distances, and environmental parameters as calculated by a dissimilarity matrix expressed as the Euclidean distances between geographic regions based on environmental data. Acropora palmata samples from four geographic regions (Florida, Bahamas, Puerto Rico and USVI) were genotyped with 307 SNP (a-c) or 10 neutral microsatellite (d) markers. Panel (a) y $=0.0107 x+0.0104, R^{2}=$ 0.610, $\mathrm{p}=0.09$. Panel (b) $\mathrm{y}=0.002 \mathrm{x}+0.4175, \mathrm{R}^{2}=0.101, \mathrm{p}=0.21$. Panel (c) $\mathrm{y}=0.000007 \mathrm{x}+$ 0.0098. $R^{2}=0.648$, p-value $=0.05$. Panel (d) $y=0.000007 x+0.0027 . R^{2}=0.69, p=0.04$. 